\title{
Development and Formation Mechanism of the Southeast Asian Winter Heavy Rainfall Events around the South China Sea. Part II: Multiple Interactions*
}

\author{
TSING-CHANG CHEN AND JENQ-DAR TSAY \\ Department of Geological and Atmospheric Sciences, Iowa State University, Ames, Iowa \\ Jun MATSUMOTO \\ Department of Geography, Tokyo Metropolitan University, Tokyo, and Research Institute for \\ Global Change, JAMSTEC, Yokosuka, Japan
}

(Manuscript received 26 February 2014, in final form 25 September 2014)

\begin{abstract}
About $44 \%$ of the cold-season heavy rainfall/flood (HRF) events around the South China Sea require six days or longer to develop from the formation time of their parent cold surge vortices (CSVs). Formations for both the parent CSV and HRF event are involved with interactions of the concerned vortices with two different cold surge flows. The occurrence frequency of the East Asian cold surge flow varies from 4.5 to 6 days. The longevous CSVs enable their developments to interact with the second cold surge flows between formations of these CSVs and HRF events. Two requirements for the formation of HRF events are 1) synchronized occurrence of the HRF event and the northwestern Pacific explosive cyclone and 2) simultaneous occurrence of the maximum speeds among westerlies of the northwestern Pacific explosive cyclone and easterlies of the tropical trade winds and the HRF event. These requirements cannot be met by the CSV at its second maximum peak intensity, but the CSV at this stage plays an indispensible role for the formation of the HRF event to make its intensity and rainfall amount larger than those HRF events without this relay intensification. The development of an HRF event through multiple interactions of CSVs with sequential cold surge flows may pose difficulties to numerically simulate/predict the occurrence of these HRF events over the cold-season rainfall centers around the South China Sea.
\end{abstract}

\section{Introduction}

An effort is made in this study to explore three development aspects of cold surge vortices (CSVs) into heavy rainfall flood (HRF) events over the winter rainfall centers around the South China Sea (SCS): 1) CSV(HRF) formation mechanism [CSV(HRF) indicates a CSV that develops into an HRF cyclone and/or noncyclone event (cyclone/event)], 2) CSV(HRF) propagation properties, and 3) development processes of HRF cyclones/events.

\footnotetext{
* Supplemental information related to this paper is available at the Journals Online website: http://dx.doi.org/10.1175/JCLI-D-1400171.s1.

Corresponding author address: Tsing-Chang (Mike) Chen, Atmospheric Science Program, Department of Geological and Atmospheric Sciences, 3010 Agronomy Hall, Iowa State University, Ames, IA 50011.

E-mail: tmchen@iastate.edu
}

New findings for the aforementioned aspects in this study include the following:

1) $\operatorname{CSV}(\mathrm{HRF})$ only form in the Philippine vicinity and Borneo by different mechanisms. The former (latter) CSV(HRF) also exhibits a formation time preference at 0600 UTC (0000 UTC) and an interaction preference with the Philippine Sea (South China Sea)-type cold surge flow within the South China Sea.

2) Seven rainfall centers around the South China Sea are established by HRF events from the Philippine vicinity and Borneo CSV(HRF). Propagation properties for CSV(HRF) across the South China Sea are determined by the flow type of cold surge in this sea.

3) The development of CSV(HRF) into HRF cyclones/ events is accomplished through the multi-interaction of CSV(HRF) with sequential cold surge flows intruding into the South China Sea and impacting the North Pacific synoptic systems. 
TABLE 1. Averaged propagation properties of CSV(HRF) across the South China Sea. The life cycle of CSV(HRF) are separated into two groups: boldface for life cycle $\sim>6$ days and italic for life cycle $<6$ days. Numbers in parentheses following all averaged values shown in columns $4-6$ are standard deviations.

\begin{tabular}{|c|c|c|c|c|c|}
\hline Item & $\begin{array}{c}\text { Formation } \\
\text { location of CSV }\end{array}$ & $\begin{array}{l}\text { Location of } \\
\text { HRF event }\end{array}$ & $\begin{array}{l}\text { Traveling time/life } \\
\text { cycle of CSV(HRF) }\end{array}$ & $\begin{array}{l}\text { Propagation } \\
\text { speed }\end{array}$ & $\begin{array}{l}\text { Distance between locations } \\
\text { of CSV(HRF) formation and } \\
\text { HRF event occurrences }\end{array}$ \\
\hline \multirow[t]{5}{*}{ West of the SCS } & \multirow[t]{3}{*}{ Philippine vicinity } & Central Vietnam & 4.5 (1.2) days & $3.7^{\circ}\left(3.5^{\circ}\right) \mathrm{day}^{-1}$ & $16.8^{\circ}\left(4.2^{\circ}\right)$ \\
\hline & & Malaysia & 7.3 (1.2) days & 3.2 ${ }^{\circ}\left(2.8^{\circ}\right)$ day $^{-1}$ & $23.4^{\circ}\left(3.4^{\circ}\right)$ \\
\hline & & Sumatra & 7.5 (1.3) days & $3.6^{\circ}\left(2.9^{\circ}\right)$ day $^{-1}$ & $26.8^{\circ}\left(3.8^{\circ}\right)$ \\
\hline & \multirow[t]{2}{*}{ Borneo } & Malaysia & 7.1 (1.2) days & $1.6^{\circ}\left(1.4^{\circ}\right)$ day $^{-1}$ & $11.2^{\circ}\left(1.7^{\circ}\right)$ \\
\hline & & Sumatra & 6.0 (1.0) days & $1.3^{\circ}\left(\mathbf{0 . 8}^{\circ}\right)$ day $^{-1}$ & $\mathbf{7 . 6}^{\circ}\left(\mathbf{0 . 8}^{\circ}\right)$ \\
\hline \multirow[t]{4}{*}{ East of the SCS } & \multirow[t]{2}{*}{ Philippine vicinity } & Northern Philippines & $2.0(0.8)$ days & $4.6^{\circ}\left(3.2^{\circ}\right) \mathrm{day}^{-1}$ & $9.1^{\circ}\left(2.6^{\circ}\right)$ \\
\hline & & Southern Philippines & $2.0(0.8)$ days & $4.6^{\circ}\left(3.5^{\circ}\right) \mathrm{day}^{-1}$ & $9.1^{\circ}\left(2.8^{\circ}\right)$ \\
\hline & \multirow[t]{2}{*}{ Borneo } & Borneo & 5.8 (1.5) days & $\mathbf{0}^{\circ}\left(\mathbf{0 . 3 ^ { \circ }}\right)$ day $^{-1}$ & $\mathbf{0}^{\circ}\left(\mathbf{0 . 5 ^ { \circ }}\right)$ \\
\hline & & Java & $5.8(1.2)$ days & $\boldsymbol{0}^{\circ}\left(\mathbf{0 . 2 ^ { \circ }}\right)$ day $^{-1}$ & $0^{\circ}\left(0.2^{\circ}\right)$ \\
\hline
\end{tabular}

The first two aspects of CSV(HRF) development processes were reported in (Chen et al. 2015, hereafter Part I) while the third aspect is the focus of this paper.

Prior to the Winter Monsoon Experiment (WMONEX; Greenfield and Krishnamurti 1979), Cheang (1977) suggested that the peninsular Malaysia HRF event develops from the western tropical Pacific easterly vortex. Following this suggestion, Yokoi and Matsumoto (2008) found that the required synoptic condition is the presence of cold surge flow for the development of HRF cyclones/events in central Vietnam. Later, Chen et al. (2012a,b) showed the HRF cyclone/event occurs when three monsoon modes (30-60, 12-24, and 5 day) exhibit a constructive, in-phase interference and synchronizes with the occurrence of a western Pacific explosive cyclone (Sanders and Gyakum 1980). In Part I, it was found the HRF cyclones/events developed only from CSV(HRF) formed in the Philippine vicinity and Borneo (Figs. 2 and 8 of Part I), instead of the western tropical Pacific easterly vortices. Observed by previous studies (Chen et al. 2012a,b, 2013a,b), the development of an HRF event from its parent CSV(HRF) involves interactions twice with cold surge flows: formations from this CSV(HRF) and the corresponding HRF event. In fact, an additional interaction of this CSV(HRF) with a cold surge flow may occur between the formations of the parent CSV(HRF) and the HRF event if this development has a life cycle $\geq 6$ days.

As observed in Part I and summarized in Table 1, the average development time for each group of CSV(HRF) (i.e., the time for these vortices to travel across the South China Sea or become stagnated east of this sea) varies on average from two to more than seven days, so their propagation speeds and distances differ greatly from each other. As inferred in Part I, the occurrence of HRF cyclones/events is likely caused by the multi-interaction of the parent CSV(HRF) with sequential cold surge flows intruding on the South China Sea and the impact of some
North Pacific synoptic systems. Thus, the primary issue addressed herein is how the CSV(HRF) develops into HRF cyclones/events through the multi-interaction of CSV(HRF) with different cold surge flows and the impact of the Pacific synoptic systems. This development process is reflected by the CSV(HRF) intensification and rainfall enhancement, which will be illustrated through a dynamic-hydrologic-thermodynamic process. This process will be elucidated by the budget analyses of vorticity, water vapor, and velocity potential, and special characteristics of certain synoptic elements in the North Pacific basin.

To pursue the goal described previously, this study is organized in the following manner. Data from Part I are also used herein; the details can be found in Part I. The possible multi-interaction to develop the CSV(HRF) into an HRF event is identified in section 2 through the chronicled development of maximum vorticity for nine CSV(HRF) groups. The interrelationships among the three budget analyses in intensifying the CSV(HRF) and maintaining the HRF event are also presented in this section. Two typical case studies for the synoptic development of CSV(HRF) into HRF cyclones/events through triple maximum intensities of CSV(HRF) with cold surge flows are illustrated as examples in section 3 . Because there were $181 \mathrm{HRF}$ events identified by the Dartmouth Flood Observatory (DFO; DFO 2013), a statistical analysis is conducted in section 4 to substantiate the CSV(HRF) development processes into HRF cyclones/events revealed from case studies in the previous section. Formation of HRF events in central Vietnam and Malaysia needs to satisfy two requirements: 1) synchronized occurrence of the HRF event and North Pacific explosive cyclone (Sanders and Gyakum 1980) and 2) simultaneous occurrence of maximum speeds between explosive cyclone westerlies and the easterlies of tropical trade winds and HRF cyclones/events (Chen et al. 2012a, 2013a). These two requirements are met by a great 
majority of all DFO HRF events, but not by the second maximum intensification of CSV(HRF) to form $\mathrm{HRF}$ events through the triple maximum intensification. Thus, the role played by the second maximum intensification of $\mathrm{CSV}(\mathrm{HRF})$ is assessed as a relay development of HRF cyclones/events in section 5. Concluding remarks of the study herein and suggestions for future efforts to explore dynamic and physical processes involved with the formation of CSV(HRF) and HRF events, and the forecast improvements of HRF events, are offered in section 6.

\section{Identification of multi-interaction $\operatorname{CSV}(\mathrm{HRF})$ and development diagnosis}

\section{a. Identification of multi-interaction CSV(HRF)}

The occurrence frequency of the East Asian cold surge may vary from 4.5 days during the warm ENSO phase to 6 days during the cold ENSO phase (e.g., Chen et al. 2004). If the averaged traveling time/life cycle of CSV(HRF) in some groups (Table 1 ) is over 4.5 days, some CSV(HRF) in these groups may have a traveling time longer than 4.5 days by considering their standard deviation time. The development of HRF cyclones/events from these longevous parent $\mathrm{CSV}(\mathrm{HRF})$ may be achieved through multiinteractions with sequential cold surge flows. To confirm this interference, a procedure to identify this multiinteraction is developed:

(i) The CSV(HRF) vorticity averaged over the area with a threshold value $\geq 1.8 \times 10^{-5} \mathrm{~s}^{-1}$ is used as an indicator of the CSV(HRF) intensity. Following the Lagrangian approach along a CSV(HRF) trajectory, the time series for this area-averaged CSV (HRF) vorticity $\zeta^{o}$ is prepared.

(ii) Following von Storch and Zwiers (2002), the linear trend of a CSV(HRF) $\zeta^{o}$ time series over its life cycle is removed. The maximum $\zeta^{o}$ exceeding one standard deviation $\left(\sigma^{\zeta^{\circ}}\right)$ of the detrended $\zeta^{o}$ time series is used to identify the maximum intensities of CSV(HRF) over their life cycles.

(iii) The identified maximum intensities of a CSV (HRF) over its life cycle are checked to see whether these maximum intensities are caused by this CSV (HRF) interactions with sequential cold surge flows whose types are determined by the procedure presented in Part I.

(iv) If the formation/occurrence of an HRF event that accompanies CSV(HRF) maximum intensity coincides with the occurrence of a northwestern Pacific explosive cycle, one should check whether this CSV (HRF) maximum intensity is caused by the interaction of a new cold surge or maintained by an aging surge. The impact by the two requirements pointed out previously in the formation/occurrence of an HRF event can be found in Chen et al. (2012b).

Following the four-step procedure described above, the time taken by a CSV(HRF) from its formation to the occurrence location of an HRF event is shown in Fig. 1. HRF cyclones/events develop from their parent CSV(HRF) and may exhibit the maximum $\zeta^{\circ}$ at $925 \mathrm{hPa}\left[\zeta^{\circ}(925 \mathrm{hPa})\right]$ intensity twice or three times. The HRF event occurs by the impact of the two requirements, in addition to the interaction of either a new or an aging cold surge. For convenience, HRF events are designated by $\mathrm{HRF}_{m}^{n}$, where $n$ represents the number of the maximum intensities their parent $\operatorname{CSV}\left(\mathrm{HRF}_{m}^{n}\right)$ undergoes and $m$ denotes the number of cold surge flows with which these $\mathrm{CSV}\left(\mathrm{HRF}_{m}^{n}\right)$ interact. As indicated by the vertical yellow stripe in Fig. $1, \mathrm{HRF}_{2}^{3}$ and $\mathrm{HRF}_{3}^{3}$ events form if the life cycles of their parent $\operatorname{CSV}\left(\mathrm{HRF}_{2}^{3}\right)$ and $\mathrm{CSV}\left(\mathrm{HRF}_{3}^{3}\right)$

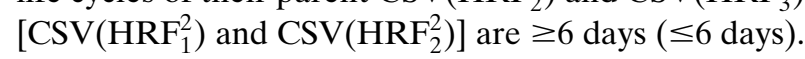
Interesting features of Fig. 1 are highlighted below.

\section{1) West of the South China Sea}

- Over central Vietnam, the population of HRF events consists of only $22 \%$ of $\mathrm{HRF}_{2}^{3}$ events, but $78 \%$ of $\mathrm{HRF}_{2}^{2}$ events. In contrast, the great majority of the HRF population in peninsular Malaysia are $\mathrm{HRF}_{2}^{3}+$ $\mathrm{HRF}_{3}^{3}$ events developed from the Philippine CSV $\left(\mathrm{HRF}_{m}^{3}\right)(78 \%)$ and $\mathrm{HRF}_{2}^{3}+\mathrm{HRF}_{3}^{3}$ events developed from the Borneo $\mathrm{CSV}\left(\mathrm{HRF}_{m}^{3}\right)(94 \%)$.

- As observed in Part I, the Philippine (Borneo) CSV (HRF) forms with the Philippine Sea (PHS)-type (SCS type) cold surge flow. In central Vietnam, the $\mathrm{HRF}_{2}^{2}$ events form in the second maximum intensities of their parent $\mathrm{CSV}\left(\mathrm{HRF}_{2}^{2}\right)$ are interacted with 13 PHS-type and 16 SCS-type cold surge flows. For the formation of $\mathrm{HRF}_{2}^{3}$ events, the second maximum intensities of their parent $\mathrm{CSV}\left(\mathrm{HRF}_{2}^{3}\right)$ interacting with 4 PHS- and 4 SCS-type cold surge flows, respectively, but these vortices are maintained by these two types of cold surge flow until they are strengthened by the impact of two requirements for the formation of the $\mathrm{HRF}_{2}^{3}$ event.

\section{2) EAst of the South China SEA}

- Over the Philippines, both the northern and southern Philippine $\mathrm{HRF}_{1}^{2}$ events develop directly from their parent Philippine CSV $\left(\mathrm{HRF}_{1}^{2}\right)$ through their interactions with only one PHS-type cold surge flow.

- For Borneo and Java, the HRF event population includes approximately $45 \%$ of $\mathrm{HRF}_{2}^{2}$ events, approximately $52 \%$ of $\mathrm{HRF}_{2}^{3}$ events, and approximately $3 \%$ of $\mathrm{HRF}_{3}^{3}$ event. These events develop through their 


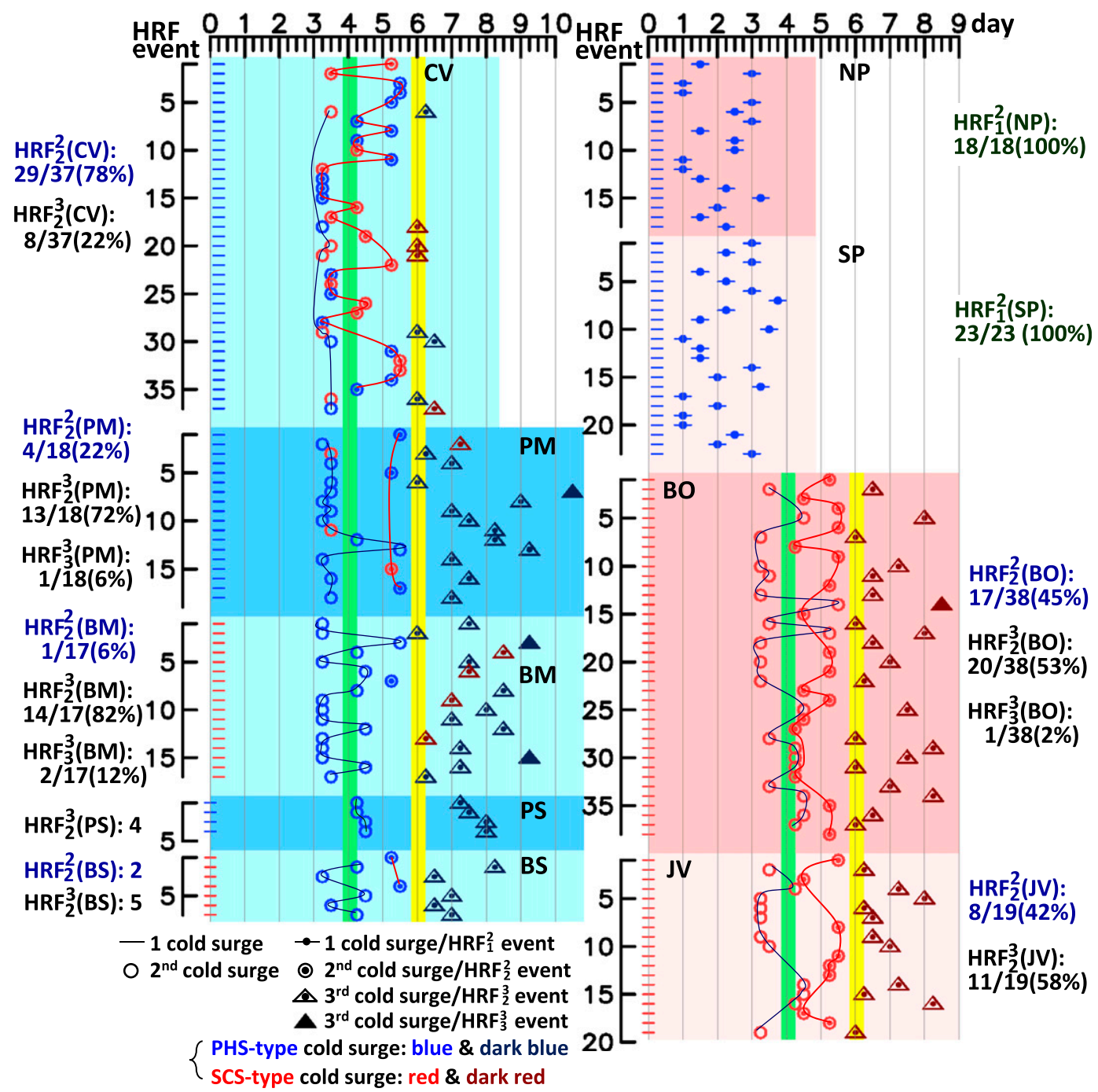

FIG. 1. The life cycle/time taken by a $\operatorname{CSV}\left(\mathrm{HRF}_{m}^{n}\right)$ to develop from its formation location to reach the formation location of the $\mathrm{HRF}_{m}^{n}$ event in seven rainfall centers. Traveling time is projected on the abscissa and the case number of $\mathrm{HRF}_{m}^{n}$ events is scaled on the ordinate. All (181) $\mathrm{HRF}_{m}^{n}$ events are classified into four groups, $\mathrm{HRF}_{3}^{3}, \mathrm{HRF}_{2}^{3}, \mathrm{HRF}_{2}^{2}$, and $\mathrm{HRF}_{1}^{2}$, and are denoted by a solid triangle, open triangle with a dot inside, open circle with a dot inside, and a short line

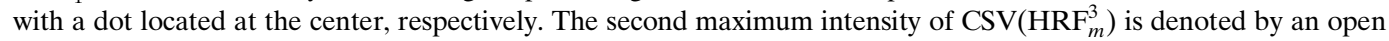
circle. The red (blue) symbol indicates the $\operatorname{CSV}\left(\mathrm{HRF}_{m}^{n}\right)$ interaction with the SCS-type (PHS type) cold surge flow. Dates of the second maximum intensity of $\operatorname{CSV}\left(\mathrm{HRF}_{m}^{3}\right)$ and occurrence of $\mathrm{HRF}_{2}^{2}$ in each rainfall center are linked by a thin blue and a thin red line, respectively. The vertical green and yellow stripes stratify the times needed to develop the second peak intensity of $\mathrm{CSV}\left(\mathrm{HRF}_{m}^{3}\right)$, and to form $\mathrm{HRF}_{2}^{2}, \mathrm{HRF}_{2}^{3}$, and $\mathrm{HRF}_{3}^{3}$ events. (A schematic diagram in Fig. 9 further illustrates this time stratification for the occurrence of these four different events.)

interactions only with two sequential SCS-type cold surge flows, except the $\mathrm{HRF}_{3}^{3}$ event develops through its interactions with three sequential SCS-type cold surge flows.

\section{b. Diagnostic budget analysis}

Our major concern in this study is how a $\operatorname{CSV}\left(\mathrm{HRF}_{m}^{n}\right)$ intensifies and develops into a $\mathrm{HRF}_{m}^{n}$ cyclone/event through the multi-interaction of $\operatorname{CSV}\left(\mathrm{HRF}_{m}^{n}\right)$ with the intrusion of East Asian cold surge flow into the South China Sea. This interaction takes place by a collision between the cold dry midlatitude air mass and the warm moist tropical perturbation in the South China Sea. Thus, a heavy rainfall event developed by the intensified cyclone system should be achieved by this midlatitude-tropic interaction through the dynamic-hydrologic-thermodynamic process. The following budget analyses will be performed to illustrate this interaction. 


\section{1) Vorticity Budget}

The strength of a vortex is often measured by the vorticity $\zeta$ over an area. Thus, the $\operatorname{CSV}(\mathrm{HRF})$ intensification may be illustrated by the vorticity tendency $\zeta_{t}$ contributed by two dynamic processes-vorticity advection $\zeta_{t}^{A}$ and vortex stretching $\zeta_{t}^{V}$ :

$$
\zeta_{t}=\underbrace{-\mathbf{V} \cdot \nabla(\zeta+f)}_{\zeta_{t}^{A}} \underbrace{-(\zeta+f) \nabla \cdot \mathbf{V}}_{\zeta_{t}^{V}},
$$

where $f=2 \Omega \sin \phi$ and $\Omega$, and $\phi$ are Earth's rotation rate and latitude, respectively, and $\mathbf{V}$ is the wind vector. The vorticity of $\operatorname{CSV}(\mathrm{HRF})$ can be distributed by $\zeta_{t}^{A}$, but is generated by convergence of the air mass flux through $\zeta_{t}^{V}$.

\section{2) WATER VAPOR BUDGET}

Rainfall is primarily maintained by the convergence of the water vapor flux. Thus, the water vapor budget may be approximated by

$$
P \sim-\nabla \cdot \mathbf{Q} .
$$

The water vapor flux $\mathbf{Q}$ can be separated into rotational $\mathbf{Q}_{R}$ and divergent $\mathbf{Q}_{D}$ components,

$$
\mathbf{Q}=\mathbf{Q}_{R}+\mathbf{Q}_{D}
$$

where $\mathbf{Q}_{D}$ can be measured by gradients of the potential function $\chi_{\mathbf{Q}}$ of water vapor flux (Chen 1985), that is, $\mathbf{Q}_{D}=\nabla \chi_{\mathbf{Q}}$. Thus, Eq. (2) may be written as

$$
P \sim-\nabla \cdot \mathbf{Q}_{D}=-\nabla^{2} \chi_{\mathbf{Q}} .
$$

Because water vapor is scalar, $\mathbf{Q}_{D}$ should be driven by the divergent flow, and $-\boldsymbol{\nabla} \cdot \mathbf{Q}_{D}$ is intensified by the convergence of air mass flux, $-\boldsymbol{\nabla} \cdot \mathbf{V}$, to enhance/ maintain rainfall of a CSV(HRF) through Eqs. (2) and (3). The spatial structure of $\chi_{\mathbf{Q}}$ should resemble that for the $\chi$ velocity potential.

\section{3) THE $\chi$ MAINTENANCE EQUATION}

The divergent circulation portrayed by velocity potential $\chi$ is often expressed by the convergence or divergence of air mass flux. The response of the atmospheric circulation to thermodynamic processes, sensible heating advection, and diabatic heating is the development of divergent circulation. Combining the continuity and thermodynamic equations, one can obtain the $\chi$ maintenance equation (Chen and Yen 1991a,b),

$$
\chi=\underbrace{\nabla^{-2}\left\{-\frac{\partial}{\partial p}\left[\frac{1}{\sigma}\left(\frac{\partial T}{\partial t}+\mathbf{V} \cdot \nabla T\right)\right]\right\}}_{\chi_{H}}+\underbrace{\nabla^{-2}\left[\frac{\partial}{\partial p}\left(\frac{1}{c_{p} \sigma} \dot{Q}\right)\right]}_{\chi_{\dot{Q}}},
$$

where $\sigma, T, c_{p}, \dot{Q}$, and $p$ are static stability, temperature, specific heat at constant pressure, diabatic heating, and pressure, respectively. The thermal tendency $\partial T / \partial t$ is usually not a significant thermal term. Thus, velocity potential is primarily maintained by the vertical differentiations of heat advection and diabatic heating:

$$
\nabla \cdot \mathbf{V}=\nabla^{2} \chi \simeq \nabla^{2} \chi_{H}+\nabla^{2} \chi_{\dot{Q}}
$$

Note that the latent heat released by condensation is a major contribution to $\dot{Q}$ (Yanai et al. 1973), so the direct atmospheric response to this heating is the development of divergent circulation. If $\chi_{H} \ll \chi_{\dot{Q}}$ and $\nabla^{2} \chi_{H} \ll \nabla^{2} \chi_{\dot{Q}}$, the divergent circulation will be strengthened by the latent heat released from cumulus convection/rainfall,

$\chi \sim \nabla^{-2}\left[\frac{\partial}{\partial p}\left(\frac{1}{c_{p} \sigma} \dot{Q}\right)\right] \sim \chi_{\dot{Q}}$ and $-\nabla \cdot \mathbf{V} \sim-\nabla^{2} \chi_{\dot{Q}}$.

\section{4) THE DYNAMIC-HYDROLOGIC-THERMODYNAMIC PROCESS TO INTENSIFY $\mathrm{CSV}\left(\mathrm{HRF}_{m}^{n}\right)$}

The enhancement of air mass flux convergence would lead to the intensification of a $\operatorname{CSV}\left(\operatorname{HRF}_{m}^{n}\right)$ through vortex stretching in Eq. (1). The intensification of a $\operatorname{CSV}\left(\mathrm{HRF}_{m}^{n}\right)$ through the multi-interaction of sequential cold surge flows can be illustrated through the interrelationship among Eqs. (1), (3), and (6). The interrelationships among the dynamical, hydrological, and thermodynamical processes to intensify CSV(HRF) may be illustrated by the following contrasts: $-\nabla \cdot \mathbf{V}$ versus $-\boldsymbol{\nabla} \cdot \mathbf{Q},-\boldsymbol{\nabla} \cdot \mathbf{Q}$ versus precipitation $(P)$, and $-\nabla \cdot \mathbf{V}_{\dot{Q}}$ versus $-\nabla \cdot \mathbf{V}$, shown in Fig. 2.

\section{Case analysis for the development of HRF cyclone/events through multi-interactions}

Despite previous efforts (Cheang 1977; Yokoi and Matsumoto 2008; Chen et al. 2012a,b, 2013a,b), the 


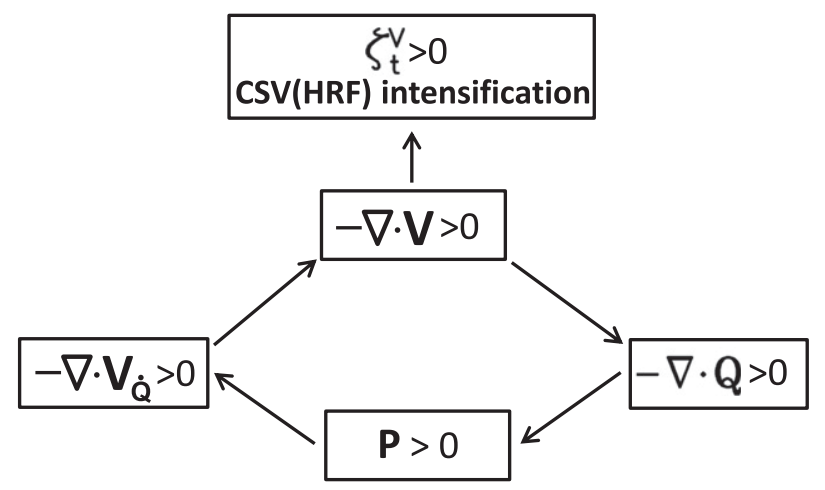

FIG. 2. Schematic diagram to illustrate of the relationship between $\zeta_{t}^{V}$ vs $-\boldsymbol{\nabla} \cdot \mathbf{V},-\boldsymbol{\nabla} \cdot \mathbf{V}$ vs $-\boldsymbol{\nabla} \cdot \mathbf{Q},-\boldsymbol{\nabla} \cdot \mathbf{Q}$ vs $P$, and $-\boldsymbol{\nabla} \cdot \mathbf{V}_{\dot{Q}}$ vs $-\boldsymbol{\nabla} \cdot \mathbf{V}$.

CSV(HRF) formation and development into HRF events through the multi-interaction of $\mathrm{CSV}(\mathrm{HRF})$ with sequential cold surge flows was not noticed. To avoid redundancy, the synoptic developments of a typical case east and another typical case west of the South China Sea are presented. The budget analyses for vorticity, water vapor, and velocity potential formulated in section 2 are performed to illustrate the $\mathrm{CSV}\left(\mathrm{HRF}_{m}^{n}\right)-\mathrm{HRF}_{m}^{n}$ development processes for one $\mathrm{HRF}_{2}^{3}$ event of these two cases. A great majority of $\mathrm{HRF}_{m}^{n}$ cyclones/events in peninsular Malaysia (PM) develop from the Philippine $\operatorname{CSV}\left(\mathrm{HRF}_{m}^{n}\right)$ through the multi-interactions with the PHS-type cold surge flows. Thus, a typical Philippine $\mathrm{CSV}\left(\mathrm{HRF}_{2}^{3}\right)-\mathrm{HRF}_{2}^{3}(\mathrm{PM})$ case is selected to illustrate the development of an $\mathrm{HRF}_{2}^{3}$ event west of the South China Sea. Over one-half of the $\mathrm{HRF}_{m}^{n}$ in Borneo (BO) cyclones/events evolve from the Borneo $\operatorname{CSV}\left(\mathrm{HRF}_{m}^{n}\right)$ through multi-interactions with the SCS-type cold surge flow. A typical Borneo $\operatorname{CSV}\left(\mathrm{HRF}_{2}^{3}\right)-\mathrm{HRF}_{2}^{3}(\mathrm{BO})$ case is chosen to depict how a $\mathrm{HRF}_{2}^{3}(\mathrm{BO})$ event develops east of the South China Sea. Four cases of $\mathrm{CSV}\left(\mathrm{HRF}_{3}^{3}\right)-\mathrm{HRF}_{3}^{3}$ are identified (Fig. 1). [To save space, the developments of a Philippine $\operatorname{CSV}\left(\mathrm{HRF}_{3}^{3}\right)-\mathrm{HRF}_{3}^{3}(\mathrm{PM})$ case and Borneo $\mathrm{CSV}\left(\mathrm{HRF}_{3}^{3}\right)-\mathrm{HRF}_{3}^{3}(\mathrm{BO})$ case are shown in the supplemental material.] Because nine groups of $\mathrm{HRF}_{m}^{n}$ events are categorized, the synoptic development and vorticity budget analysis for a typical case of the remaining seven groups, perhaps through either single, double, or triple interactions with sequential cold surge flows, are posted online (http://eamex.iastate.edu/ publication/SEAsia_HRF_partII_supp.pdf).

a. Case 1: Development of a Malaysia $\mathrm{HRF}_{2}^{3}$ event from its parent Philippine $\operatorname{CSV}\left(\mathrm{HRF}_{2}^{3}\right)$

\section{1) Vorticity TIME SERIES}

Following the evolution from its formation time at 0600 UTC 4 November 2010 (Fig. 3b) into a peninsular
Malaysia $\mathrm{HRF}_{2}^{3}$ event at 1200 UTC 9 November 2010 (Fig. 3d), the time series of $\zeta^{o}(925 \mathrm{hPa})$ for $\mathrm{CSV}\left(\mathrm{HRF}_{2}^{3}\right)$ is shown in Fig. 3a. Attached to this time series is the time series for the $925-\mathrm{hPa}$ wind vector $[\mathbf{V}(925 \mathrm{hPa})]$ at the maximum isotach location of the related northeastern Asia cold surge (indicated in Figs. 3b-d). Using the identification procedure in section $2 \mathrm{a}$, three $\zeta^{\circ}(925 \mathrm{hPa})$ maxima emerge at 0600 UTC 4 November 2010, 0600 UTC 7 November 2010, and 1200 UTC 9 November 2010. Shown by the $\mathbf{V}(925 \mathrm{hPa})$ time series on the top of Fig. 3a, the three $\zeta^{o}(925 \mathrm{hPa})$ maxima are responses for this $\operatorname{CSV}\left(\mathrm{HRF}_{2}^{3}\right)$ interactions with the sequential intrusions of the two cold surge flows (indicated by red vectors) and the strengthened basin-scale circulation related to the northwestern Pacific explosive cyclone. The development of the $\mathrm{HRF}_{2}^{3}(\mathrm{PM})$ cyclone/event is reflected by the increasing intensification of these three $\zeta^{o}(925 \mathrm{hPa})$ maxima from $2.3 \times 10^{-5} \mathrm{~s}^{-1}$ (first maximum) to $3.1 \times 10^{-5} \mathrm{~s}^{-1}$ (third maximum) through the following processes: 1) a linear increasing trend of the $\mathrm{CSV}\left(\mathrm{HRF}_{2}^{3}\right)$ diurnal variation of its vorticity across the South China Sea, 2) the responses from the $\operatorname{CSV}\left(\mathrm{HRF}_{2}^{3}\right)$ interaction with the sequential intrusions of the two cold surge flows marked by red vectors on the $\mathbf{V}(925 \mathrm{hPa})$ time series, and 3) the intensified tropical trades coupled with the occurrence of the northwestern Pacific explosive cyclone. The multi-interactions of $\operatorname{CSV}\left(\mathrm{HRF}_{2}^{3}\right)$ with cold surge flows and the tropical trade easterlies are further illustrated by the $925-\mathrm{hPa}$ streamline charts (Figs. 3b,c), when the $\operatorname{CSV}\left(\mathrm{HRF}^{3}\right)$ reaches its three $\zeta^{o}(925 \mathrm{hPa})$ maxima in Fig. 3a.

\section{2) Vorticity BUdGet ANALYSIS}

Inferred from the $\zeta^{\circ}(925 \mathrm{hPa})$ time series and the 925-hPa streamline charts (Fig. 3), the development of the $\mathrm{HRF}_{2}^{3}(\mathrm{PM})$ cyclone/event through the multi-interaction of a $\operatorname{CSV}\left(\mathrm{HRF}_{2}^{3}\right)$ with sequential cold surge flows can be substantiated by the vorticity budget analysis of Eq. (1). Because of the interaction of a Philippine $\operatorname{CSV}\left(\mathrm{HRF}_{2}^{3}\right)$ with the PHS-type cold surge flow, the strong easterlies for this cold surge flow allows this $\operatorname{CSV}\left(\mathrm{HRF}_{2}^{3}\right)$ to propagate westward, as indicated by $\zeta_{t}^{A}$. The intensification of this $\operatorname{CSV}\left(\mathrm{HRF}_{2}^{3}\right)$ may be also enhanced by the horizontal convergence of air mass flux through vortex stretching. According to Eq. (1), vorticity can be obtained by integrating this equation through a central finite difference approach:

$$
\zeta^{C}(t+\Delta t)=\zeta^{C}(t-\Delta t)+\int_{t-\Delta t}^{t+\Delta t} \zeta_{t}^{O}(t) 2 d t
$$

Using Eq. (7), the time series for $\zeta^{C}(925 \mathrm{hPa})$ and $\zeta^{o}(925 \mathrm{hPa})$ averaged over this $\mathrm{CSV}\left(\mathrm{HRF}_{2}^{3}\right)$ domain with 


\section{$\mathrm{HRF}_{2}^{3}(\mathrm{PM})$ event}

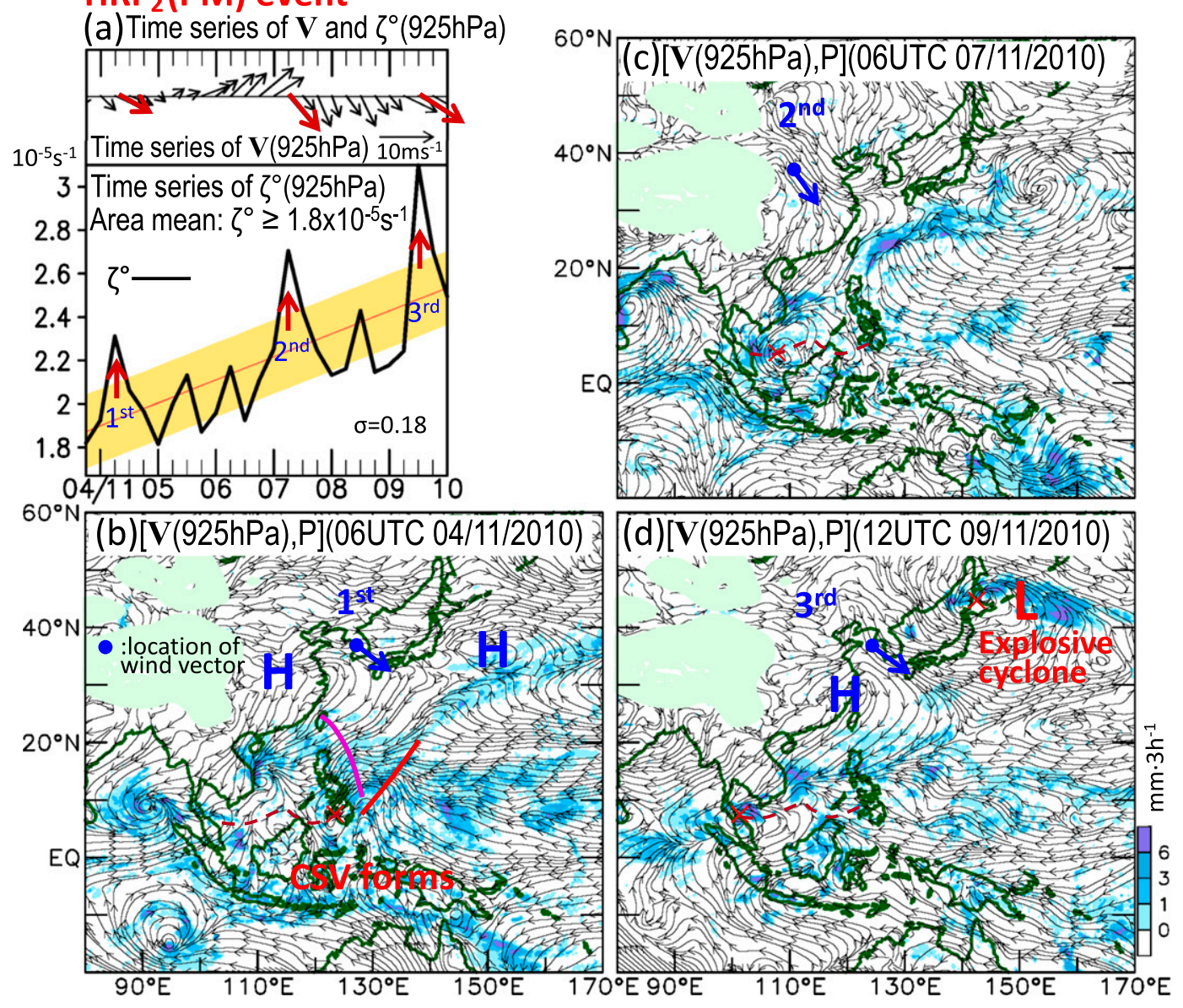

FIG. 3. Synoptic development of a Philippine $\operatorname{CSV}\left(\mathrm{HRF}_{2}^{3}\right)$ from its formation at 0600 UTC 4 Nov 2010 into a peninsular Malaysia $\mathrm{HRF}_{2}^{3}$ event at $1200 \mathrm{UTC} 9$ Nov 2010. (a) Time series for $\zeta^{o}(925 \mathrm{hPa})$, which is $\zeta(925 \mathrm{hPa})$ averaged over the area of the Philippine $\operatorname{CSV}\left(\mathrm{HRF}^{3}\right)$ with $\zeta(925 \mathrm{hPa}) \geq 1.8 \times 10^{-5} \mathrm{~s}^{-1}$. This $\zeta^{o}(925 \mathrm{hPa})$ time series is prepared with the Lagrangian approach following this $\mathrm{CSV}\left(\mathrm{HRF}_{2}^{3}\right)$ trajectory. The $\zeta^{o}(925 \mathrm{hPa})$ trend (thin red line) generated by a least squares fit approach is superimposed on the $\zeta^{\circ}(925 \mathrm{hPa}$ ) time series. One std dev (wide yellow stripe $)$ is added on the $\zeta^{\circ}(925 \mathrm{hPa})$ trend. The time series for $\mathbf{V}(925 \mathrm{hPa})$, with the maximum isotach associated with the northeastern Asia cold surge juxtaposed with a surface high and low or the maximum isotach over Bohai and the Yellow Sea, is shown at the top of (a). (b)-(d) The maximum cold surges at the three (maximum) peak intensities of the Philippine $\operatorname{CSV}\left(\mathrm{HRF}_{2}^{3}\right)$ are marked by thick red arrows on the $\mathbf{V}(925 \mathrm{hPa})$ time series and also on the $925-\mathrm{hPa}$ streamline charts with thick blue arrows. As indicated by the $\zeta^{\circ}(925 \mathrm{hPa})$ time series, $\mathrm{CSV}\left(\mathrm{HRF}_{2}^{3}\right)$ reaches its three maximum intensities, indicated by $\zeta^{\circ}(925 \mathrm{hPa}) \geq 1 \mathrm{std}$ dev in the $\zeta^{\circ}(925 \mathrm{hPa})$ time series. The $925-\mathrm{hPa}$ streamline charts superimposed with $P$ at these three special times are also shown. During the $\operatorname{CSV}\left(\operatorname{HRF}_{2}^{3}\right)$ formation at 0600 UTC 4 Nov 2010, the island-chain trough, the easterly wave, the $\operatorname{CSV}\left(\mathrm{HRF}_{2}^{3}\right)$ formation location, and the trajectory of $\mathrm{CSV}\left(\mathrm{HRF}_{2}^{3}\right)$ are marked in (b) by a solid purple line, red line, red cross, and red dashed lines, respectively. The location where $\mathrm{CSV}\left(\mathrm{HRF}_{2}^{3}\right)$ reaches its second maximum intensity is marked by a red cross in (c). Red crosses mark the locations for the Malaysia $\mathrm{HRF}_{2}^{3}$ event and the northwestern Pacific explosive cyclone in (d). The latter is also denoted by a boldface red letter $\mathrm{L}$.

$\zeta(925 \mathrm{hPa}) \geq 1.8 \times 10^{-5} \mathrm{~s}^{-1}$ are shown in Fig. $4 \mathrm{a}$; ratios for $\bar{\zeta}^{C}(925 \mathrm{hPa}) / \bar{\zeta}^{o}(925 \mathrm{hPa})$ and $\operatorname{RMS}\left[\zeta^{C}(925 \mathrm{hPa})\right] /$ [ $\left.\zeta^{\circ}(925 \mathrm{hPa})\right]$ are $98 \%$ and $99 \%$, respectively, where the overbar and RMS denote the time mean and rootmean-square of the values, respectively. Additionally, the correlation coefficient $\sigma\left(\zeta^{C}, \zeta^{o}\right)=0.95$. These statistics strongly indicate that the intensification of this
$\mathrm{CSV}\left(\mathrm{HRF}_{2}^{3}\right)$ is well determined by both $\zeta_{t}^{A}(925 \mathrm{hPa})$ and $\zeta_{t}^{V}(925 \mathrm{hPa})$ processes.

The time series for $\zeta_{t}^{o}(925 \mathrm{hPa}), \zeta_{t}^{A}(925 \mathrm{hPa})$, and $\zeta_{t}^{V}(925 \mathrm{hPa})$ averaged over this $\mathrm{CSV}\left(\mathrm{HRF}_{2}^{3}\right)$ domain $\zeta(925 \mathrm{hPa}) \geq 1.8 \times 10^{-5} \mathrm{~s}^{-1}$ are also shown in Fig. 4a. Ratios of $\operatorname{RMS}\left[\zeta_{t}^{A}(925 \mathrm{hPa})\right] / \operatorname{RMS}\left[\zeta_{t}^{o}(925 \mathrm{hPa})\right]$ and $\operatorname{RMS}\left[\zeta_{t}^{V}(925 \mathrm{hPa})\right] / \operatorname{RMS}\left[\zeta_{t}^{o}(925 \mathrm{hPa})\right]$ are $54 \%$ and 


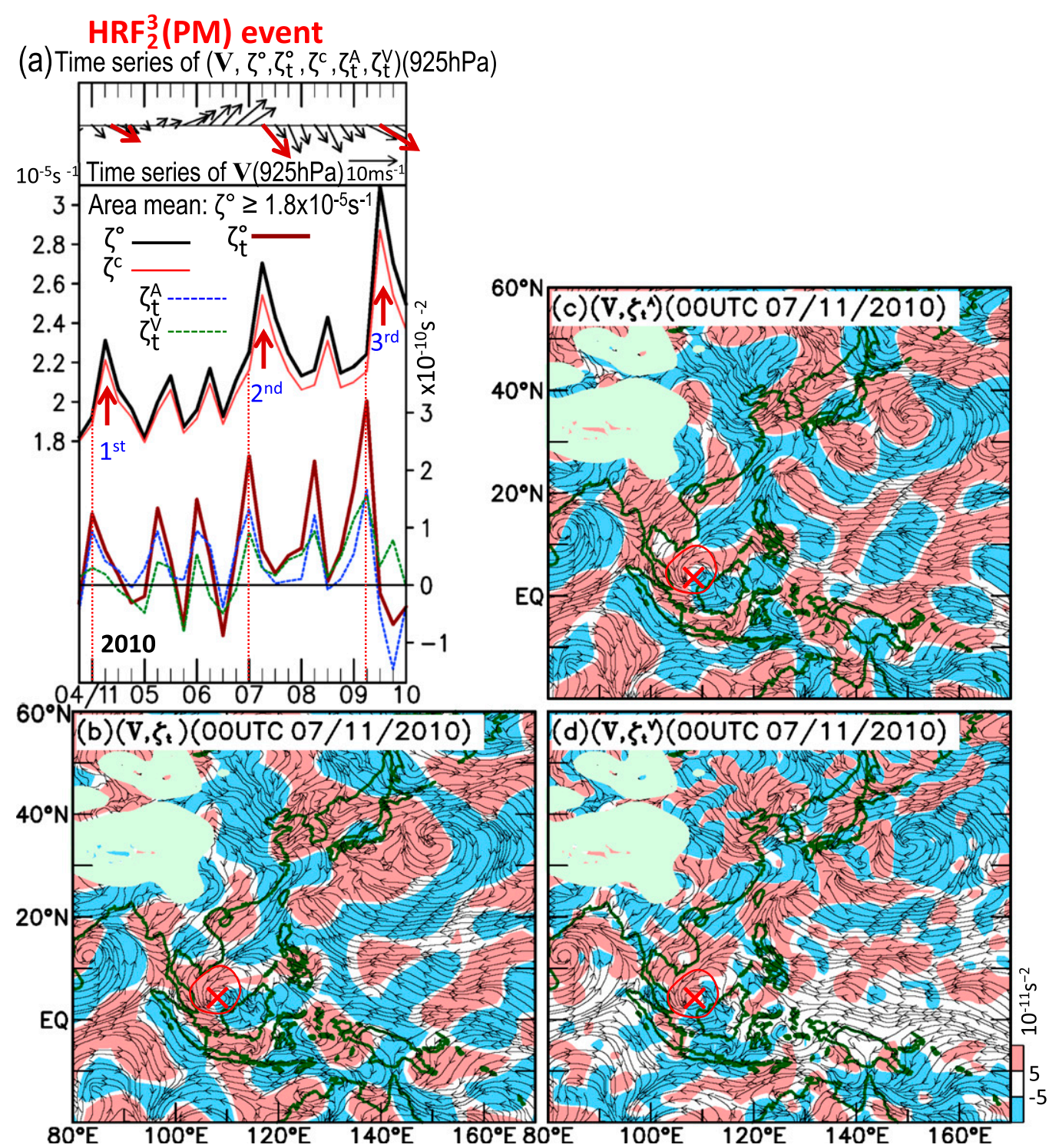

FIG. 4. The vorticity budget analysis for the Philippine $\mathrm{CSV}\left(\mathrm{HRF}_{2}^{3}\right)$, when it reaches the second maximum intensity at 0000 UTC 7 Nov 2010 (Fig. 3). (a) Time series for $\mathbf{V}$ and $\zeta^{o}$ at $925 \mathrm{hPa}$ in Fig. 3 a are added with time series for $\zeta^{C}, \zeta_{t}$, $\zeta_{t}^{A}$, and $\zeta_{t}^{V}$ at $925 \mathrm{hPa}$. The $925-\mathrm{hPa}$ streamline charts are superimposed with (b) $\zeta_{t}$, (c) $\zeta_{t}^{A}$, and (d) $\zeta_{t}^{V}$ at $925 \mathrm{hPa}$. The open red circle is the area of $\operatorname{CSV}\left(\mathrm{HRF}_{2}^{3}\right)$ with $\zeta(925 \mathrm{hPa}) \geq 1.8 \times 10^{-5} \mathrm{~s}^{-1}$ and the $\operatorname{CSV}\left(\mathrm{HRF}_{2}^{3}\right)$ center is indicated by a red cross.

$46 \%$, respectively. Correlation coefficients $\sigma\left[\zeta_{t}^{A}(925 \mathrm{hPa})\right.$, $\left.\zeta_{t}^{o}(925 \mathrm{hPa})\right]$, and $\sigma\left[\zeta_{t}^{V}(925 \mathrm{hPa}), \zeta_{t}^{o}(925 \mathrm{hPa})\right]$ are 0.87 and 0.79 , respectively. Judging by the time series for $\zeta_{t}^{o}(925 \mathrm{hPa}), \zeta_{t}^{A}(925 \mathrm{hPa})$, and $\zeta_{t}^{V}(925 \mathrm{hPa})$, the intensification of this $\operatorname{CSV}\left(\mathrm{HRF}^{3}\right)$ over its life cycle is essentially attributed to the aggregative effects of both $\zeta_{t}^{A}(925 \mathrm{hPa})$ and $\zeta_{t}^{V}(925 \mathrm{hPa})$ processes.

Note that $\zeta_{t}^{o}(925 \mathrm{hPa})$ reaches its three specially amplified maxima $6 \mathrm{~h}$ prior to the three $\zeta_{t}^{o}(925 \mathrm{hPa})$ maximum. For this reason, we select 0000 UTC 7 November $2010\left[6 \mathrm{~h}\right.$ before $\zeta_{t}^{o}(925 \mathrm{hPa})$ reaches its second maximum in Fig. 3a] to illustrate the relay intensification for this Philippine $\mathrm{CSV}\left(\mathrm{HRF}_{2}^{3}\right)$ by dynamic processes included in the vorticity equation, Eq. (1). Horizontal distributions for $\zeta_{t}(925 \mathrm{hPa}), \zeta_{t}^{A}(925 \mathrm{hPa})$, and $\zeta_{t}^{V}(925 \mathrm{hPa})$ are shown in Figs. $4 \mathrm{~b}-\mathrm{d}$ and are characterized by the following features:

(i) Divided across the center of this $\operatorname{CSV}\left(\mathrm{HRF}_{2}^{3}\right)$ (Fig. 4c), the positive and negative values for $\zeta_{t}^{A}(925 \mathrm{hPa})$ are located over the western and southeastern part of this vortex, respectively. This 
spatial structure of $\zeta_{t}^{A}(925 \mathrm{hPa})$ facilitates the westward propagation of this $\mathrm{CSV}\left(\mathrm{HRF}_{2}^{3}\right)$.

(ii) The spatial relationship between $\zeta_{t}^{V}$ and the CSV $\left(\mathrm{HRF}_{2}^{3}\right)$ is similar to that between $\zeta_{t}^{A}$ and this vortex. The interaction of this vortex with the cold surge flow through the convergence of air mass flux and vortex stretching strengthens the $\zeta_{t}^{A}$ effect.

(iii) The close variations of $\zeta_{t}^{o}(925 \mathrm{hPa})$ and $\zeta^{C}(925 \mathrm{hPa})$ in Fig. 4a indicate the second $\zeta_{t}^{o}(925 \mathrm{hPa})$ maximum is developed constructively by a combination of $\zeta_{t}^{A}(925 \mathrm{hPa})$ and $\zeta_{t}^{V}(925 \mathrm{hPa})$.

Time variations of the Philippine $\mathrm{CSV}\left(\mathrm{HRF}_{2}^{3}\right)$ vorticity budget over its life cycle (Fig. 4a) and horizontal charts for this budget at 0000 UTC 7 November 2010, $6 \mathrm{~h}$ before this vortex reaches its second maximum intensity (Figs. 4b-d), indicate that both $\zeta_{t}^{A}$ and $\zeta_{t}^{V}$ contribute

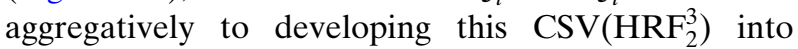
a peninsular Malaysia $\mathrm{HRF}^{3}$ cyclone/event. This $\mathrm{CSV}\left(\mathrm{HRF}_{2}^{3}\right)$ intensification by the second cold surge flow in the middle of the South China Sea is a relay interaction to maintain/allow this vortex to continuously interact with this second cold surge flow. Eventually, this $\mathrm{CSV}\left(\mathrm{HRF}_{2}^{3}\right)$ vortex also intensifies by the strengthened tropical trade easterlies into a peninsular Malaysia HRF cyclone/event.

\section{3) ANALYSIS OF WATER VAPOR BUDGET AND $\chi$ MAINTENANCE EQUATION}

It is revealed from Fig. 4d that the dynamic development process of the Philippine $\mathrm{CSV}\left(\mathrm{HRF}_{2}^{3}\right)$ relay interaction is accompanied by the convergence of the air mass flux, $-\boldsymbol{\nabla} \cdot \mathbf{V}$ (Fig. 5d), which plays a dual role in developing this $\operatorname{CSV}\left(\mathrm{HRF}_{2}^{3}\right)$. First, this convergence of air mass flux intensifies the $\mathrm{CSV}\left(\mathrm{HRF}_{2}^{3}\right)$ through vortex stretching (Fig. 4d). Second, according to Fig. 2, the convergence of water vapor flux toward the $\mathrm{CSV}\left(\mathrm{HRF}_{2}^{3}\right)$ center follows the convergence of air mass flux. This inference is confirmed by the spatial coincidence between centers of $-\boldsymbol{\nabla} \cdot \mathbf{Q}$ (Fig. 5b) and $-\boldsymbol{\nabla} \cdot \mathbf{V}$ (Fig. 5d), and by the temporal coincidence between the time series for both convergence variables averaged over the area of $P \geq 46 \mathrm{~mm}^{\circ}{ }^{-1}$, that is, $(-\boldsymbol{\nabla} \cdot \mathbf{V})^{o}$ and $(-\boldsymbol{\nabla} \cdot \mathbf{Q})^{o}$ (Fig. 5a).

The $P^{o}$ and $(-\nabla \cdot \mathbf{Q})^{o}$ time series for the $\operatorname{CSV}\left(\mathrm{HRF}_{2}^{3}\right)$ (Fig. 5a) are temporally coincident, and the centers for these two variables (Fig. 5b) are spatially coincident, too. Apparently, the rainfall increase for the CSV $\left(\mathrm{HRF}_{2}^{3}\right)$ by the second PHS-type surge flow is supplied by the enhanced convergence of water vapor flux, as indicated by Eq. (2). Illustrated by Yanai et al. (1973), an essential part of the apparent diabatic heating $\dot{Q}$ is contributed by the latent heat from condensation $L$ released by convection/precipitation, that is,

$$
\frac{1}{g} \int_{p_{s}}^{p} \dot{Q} d p \sim L P \sim-L \nabla \cdot \mathbf{Q}
$$

where $p$ and $p_{s}$ are pressures at a given level and surface, respectively.

Shown by Eq. (4), for the $\chi$ maintenance equation, $\chi$ is essentially contributed by $\chi_{H}$ and $\chi_{\dot{Q}}$. The contribution ratio by these two variables on the $\mathrm{CSV}\left(\mathrm{HRF}_{2}^{3}\right)$ domain $\left(P \geq 46 \mathrm{~mm} \mathrm{day}^{-1}\right)$ is about 1:7. Thus, we may approximate Eq. (5) by

$$
-\nabla \cdot \mathbf{V}\left(\equiv-\nabla^{-2} \chi\right) \sim-\nabla^{2} \chi_{\dot{Q}},
$$

so the convergence of air mass flux (Fig. 5d) is related to the heat for condensation by convection/rainfall (Fig. 5c) over the $\mathrm{CSV}\left(\mathrm{HRF}_{2}^{3}\right)$ center. In addition to this spatial coincidence, the correlation coefficient between $(-\nabla \cdot \mathbf{Q})^{o}$ and $\left(-\nabla^{2} \chi_{\dot{Q}}\right)^{o}$ is 0.92 .

\section{b. Case 2: Development of a Borneo $\mathrm{HRF}_{2}^{3}$ event from its in situ parent $C S V\left(H R F^{3}\right)$}

\section{1) TIME SERIES AND BUdGet ANALYSIS OF VORTICITY}

The development of a Borneo $\mathrm{HRF}_{2}^{3}$ cyclone/event from its in situ parent $\mathrm{CSV}\left(\mathrm{HRF}_{2}^{3}\right)$ over its life cycle, 18 25 December 2011, is used as an example to illustrate how its development is affected by the multi-interaction of this vortex with the sequential cold surge flows and the intensified tropical trades linked to the occurrence of a northwestern Pacific explosive cyclone. The time series of $\zeta^{o}(925 \mathrm{hPa})$ for this Borneo $\mathrm{CSV}\left(\mathrm{HRF}_{2}^{3}\right)$ over its life cycle is shown in Fig. 6a. Although $\zeta^{o}(925 \mathrm{hPa})$ undergoes a distinct diurnal variation, three specially amplified $\zeta^{\circ}(925 \mathrm{hPa})$ maxima $(>1$ standard deviation from the linear trend) emerge at 0000 UTC 18 December 2011, 1200 UTC 22 December 2011, and 0000 UTC 25 November 2011. The contrast between wind vectors for the three East Asian cold surges and the three $\zeta^{\circ}(925 \mathrm{hPa})$ maxima indicates the chronicled intensification of this Borneo $\mathrm{CSV}\left(\mathrm{HRF}_{2}^{3}\right)$ is through its multi-interactions with two sequential SCS-type cold surge flows and tropical trade easterlies. This assessment is further confirmed by the $925-\mathrm{hPa}$ streamline charts for these three special times (Figs. 6b-d) - the connection between the northeastern Asia cold surge wind vector (east of the southern Korean Peninsula) and the Borneo CSV $\left(\mathrm{HRF}_{2}^{3}\right)$ by the East Asia-South China Sea cold surge flow. As revealed from the continuous increase of $\zeta^{\circ}(925 \mathrm{hPa})$ maximum values, the intensification trend for $\mathrm{CSV}\left(\mathrm{HRF}_{2}^{3}\right)$ is initiated from the Borneo $\operatorname{CSV}\left(\mathrm{HRF}_{2}^{3}\right)$ formation to the Borneo $\mathrm{HRF}_{2}^{3}$ event occurrence. 


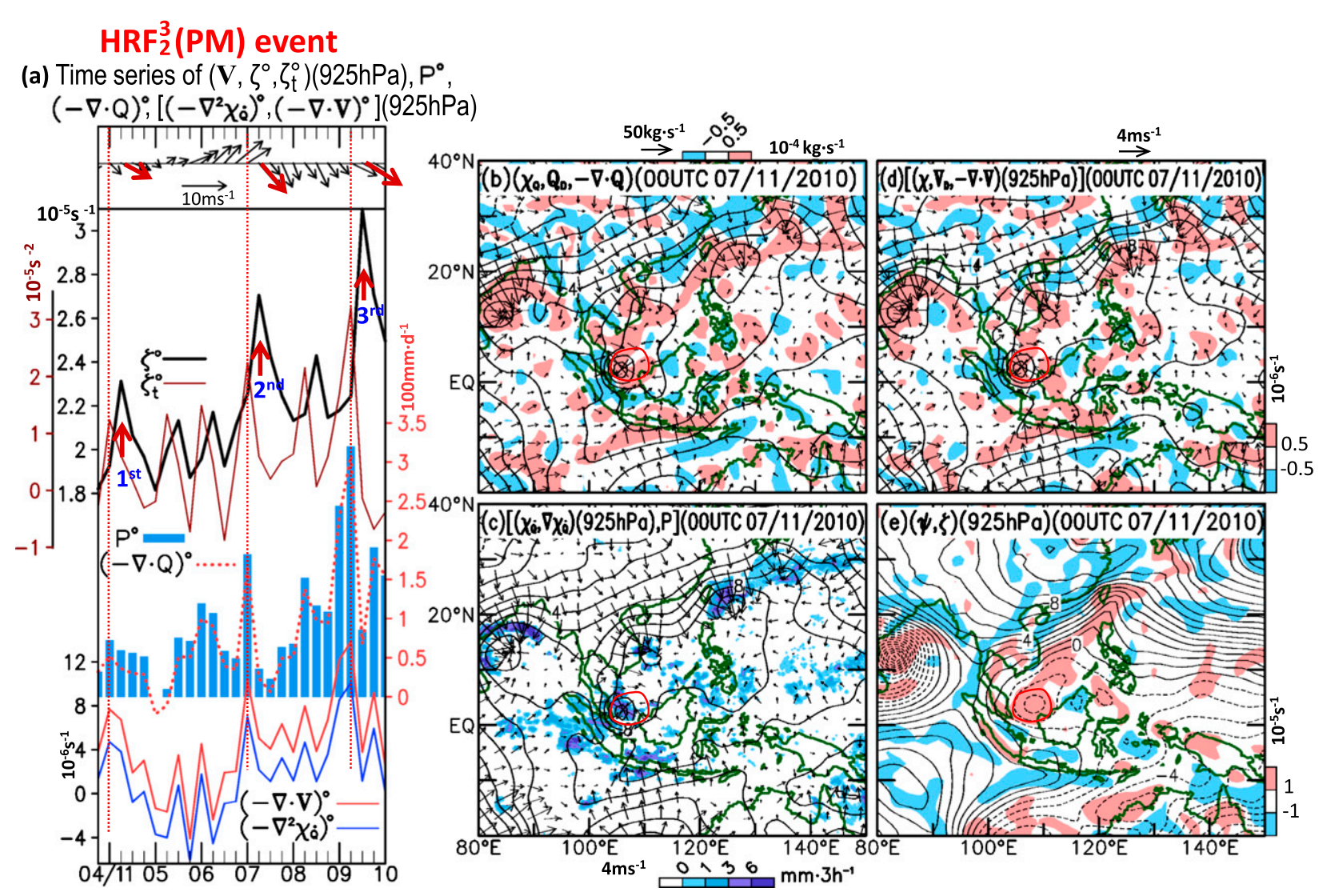

FIG. 5. As in Fig. 4, but for analyses of the water vapor budget and the $\chi$ maintenance equation for the CSV(HRF $\left.{ }_{2}^{3}\right)$ at $0000 \mathrm{UTC} \mathrm{Nov}$ 2010. (a) Time series for $\mathbf{V}(925 \mathrm{hPa}) / \zeta^{o}(925 \mathrm{hPa})$ of Fig. 3a are added to the top of Fig. 3a. Presented below it are the time series of $\zeta_{t}$ and $\zeta_{t}^{o}$ at $925 \mathrm{hPa}$, the time series of $(-\nabla \cdot \mathbf{Q})^{o}$ and a histogram of $P^{o}$, and time series of $(-\nabla \cdot \mathbf{V})^{o}$ and $\left(-\nabla^{2} \chi_{\dot{O}}\right)^{o}$ at $925 \mathrm{hPa}$. On the right of (a) are horizontal distributions of (b) $\chi_{D}, \mathbf{Q}_{D}$, and $-\nabla \cdot \mathbf{Q}$; (c) $\chi_{\dot{Q}}$ and $\nabla \chi_{\dot{Q}}$ at $925 \mathrm{hPa}$ and $P$; (d) $\chi, \mathbf{V}_{D}$, and $-\nabla \cdot \mathbf{V}$ at $925 \mathrm{hPa}$; and (e) $\psi$ and $\zeta$ at $925 \mathrm{hPa}$.

Integrating $\zeta^{\circ}(925 \mathrm{hPa})$ in time with Eq. (7), the $\zeta^{C}(925 \mathrm{hPa})$ time series is comparable to the $\zeta^{o}(925 \mathrm{hPa})$ time series in Fig. 7a; ratios of $\zeta^{C}(925 \mathrm{hPa}) / \zeta^{\circ}(925 \mathrm{hPa})$ and $\operatorname{RMS}\left[\zeta^{C}(925 \mathrm{hPa})\right] / \operatorname{RMS}\left[\zeta^{\circ}(925 \mathrm{hPa})\right]$ are $96 \%$ and $96 \%$, respectively, and the correlation coefficient $\sigma\left[\zeta^{C}(925 \mathrm{hPa}), \zeta^{o}(925 \mathrm{hPa})\right]$ is 0.94 . Apparently, the temporal variation for $\zeta^{\circ}(925 \mathrm{hPa})$ is primarily attributed to two dynamic processes $-\zeta_{t}^{A}(925 \mathrm{hPa})$ and $\zeta_{t}^{V}(925 \mathrm{hPa})$. Actually, the ratio RMS $\left[\zeta_{t}^{A}(925 \mathrm{hPa})\right] /\left[\zeta_{t}^{V}(925 \mathrm{hPa})\right]$ over the life cycle for this Borneo $\operatorname{CSV}\left(\mathrm{HRF}_{2}^{3}\right)$ is about $50 \%$. Thus, $\zeta_{t}^{o}(925 \mathrm{hPa})$ is contributed more by $\zeta_{t}^{V}(925 \mathrm{hPa})$. Note that the role played by the two dynamic processes $\zeta_{t}^{A}(925 \mathrm{hPa})$ and $\zeta_{t}^{V}(925 \mathrm{hPa})$ to intensify this Borneo $\mathrm{CSV}\left(\mathrm{HRF}_{2}^{3}\right)$ is opposite that for the Philippine $\operatorname{CSV}\left(\mathrm{HRF}_{2}^{3}\right)$.

Shown in Fig. 6a, the formation of the parent Borneo $\mathrm{CSV}\left(\mathrm{HRF}_{2}^{3}\right)$ and the ensuing $\mathrm{HRF}_{2}^{3}$ cyclone/event in the present case are accomplished by the first and second interactions of this $\mathrm{CSV}\left(\mathrm{HRF}_{2}^{3}\right)$ with the SCS-type cold surge flow, respectively, and the maintenance of this $\operatorname{CSV}\left(\mathrm{HRF}_{2}^{3}\right)$ until its final intensification by the tropical trade easterlies. Let us focus on the role played by the second interaction with an SCS-type cold surge flow in developing this vortex through the horizontal distributions of the dynamic processes in the vorticity budget. Thus, $6 \mathrm{~h}$ before $\zeta^{o}(925 \mathrm{hPa})$ for this $\mathrm{CSV}\left(\mathrm{HRF}_{2}^{3}\right)$ reaches its second maximum, the vorticity budget at 0600 UTC 22 December 2011 is selected to illustrate these processes in Figs. 7b-d. The centers for three different vorticity tendencies are coincident with this $\operatorname{CSV}\left(\mathrm{HRF}_{2}^{3}\right)$. The in situ development for this Borneo $\operatorname{CSV}\left(\mathrm{HRF}_{2}^{3}\right)$ is reflected by this spatial coincidence of these three centers. Different from case 1, the nonpropagation property for this Borneo $\operatorname{CSV}\left(\mathrm{HRF}_{2}^{3}\right)$ is reflected by the fact there is no positive $\zeta_{t}(925 \mathrm{hPa})$ west of the vortex center, because $\zeta_{t}^{A}(925 \mathrm{hPa})$ does not show such a spatial structure to support the westward propagation of the $\mathrm{CSV}\left(\mathrm{HRF}_{2}^{3}\right)$ (Chen et al. 2013a). On the other hand, the SCS-type cold surge flow intensifies the cyclonic shear flow around Borneo, which leads to the enhancement of the air mass flux convergence, and, in turn, the vortex stretching $\zeta_{t}^{V}$.

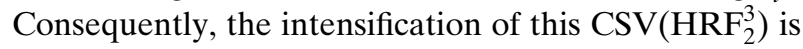


$\mathrm{HRF}_{2}^{3}$ (BO) event

(a) Time series of $\mathbf{V}$ and $\zeta^{\circ}(925 \mathrm{hPa})$

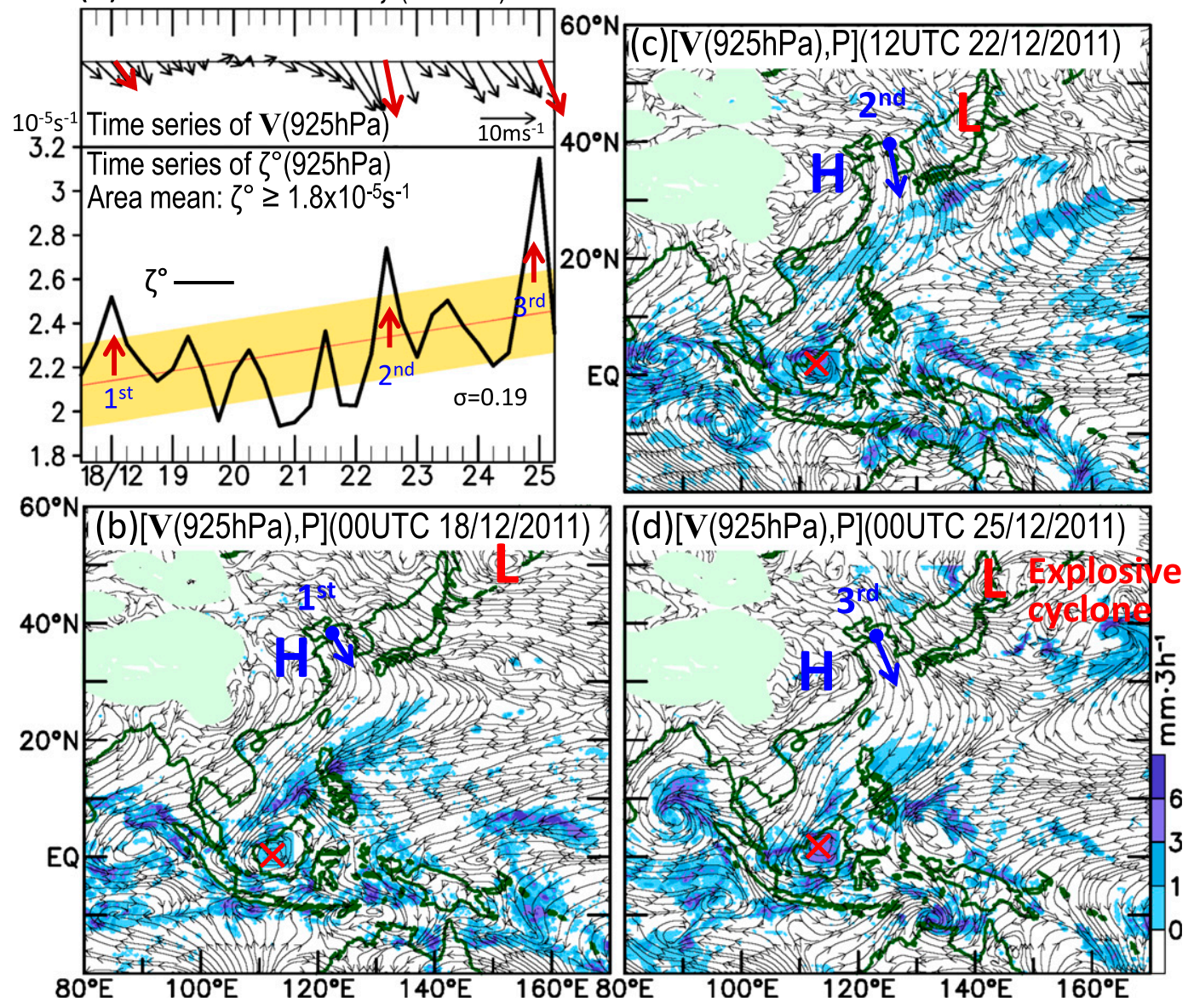

FIG. 6. As in Fig. 3, but for a Borneo CSV(HRF 2 ) with a life cycle from 0000 UTC 18 Dec to 0000 UTC 25 Dec 2011.

largely achieved by vortex stretching. The smaller value of $\zeta_{t}^{A}(925 \mathrm{hPa})$, compared to $\zeta_{t}^{V}(925 \mathrm{hPa})$, is consistent with the nonpropagation property of the Borneo $\operatorname{CSV}\left(\mathrm{HRF}_{2}^{3}\right)$ (Chen et al. 2013a).

In view of the intensification of the $\mathrm{CSV}\left(\mathrm{HRF}_{2}^{3}\right)$ to become a Borneo $\mathrm{HRF}_{2}^{3}$ event through the $\mathrm{CSV}\left(\mathrm{HRF}_{2}^{3}\right)$ interactions with two sequential cold surge flows and the final intensification by the intensified tropical trade easterlies (Figs. 6a and 7a), the second interaction is a relay dynamic process in this $\mathrm{HRF}_{2}^{3}$ development.

\section{2) ANALYSES OF THE WATER VAPOR BUDGET AND $\chi$ MAINTENANCE EQUATION}

Following the intensification of the Borneo cyclonic shear flow by the second interaction of the Borneo $\mathrm{CSV}\left(\mathrm{HRF}_{2}^{3}\right)$ with the SCS-type cold surge flow on 22 December 2011, the convergence of the air mass flux toward Borneo (Fig. 8d) is enhanced (Fig. 8a). This air mass flux convergence strengthens not only the vortex stretching, but also the convergence of the water vapor flux (shown by Fig. 2). The high correlation (with a coefficient of 0.86) between time series of $(-\boldsymbol{\nabla} \cdot \mathbf{V})^{o}$ and $(-\nabla \cdot \mathbf{Q})^{o}$ shown in Fig. 8a confirms this relationship. According to Eqs. (4) and (5), the second rainfall maximum for this $\mathrm{CSV}\left(\mathrm{HRF}_{2}^{3}\right)$ on 22 November 2011 (Fig. 8c) is maintained by the enhancement of this $\operatorname{CSV}\left(\mathrm{HRF}_{2}^{3}\right)$ $-\boldsymbol{\nabla} \cdot \mathbf{Q}$ (Fig. 8b). This observation is substantiated by the correlation coefficient of 0.91 , and ratio of mean and RMS values between $(-\nabla \cdot \mathbf{Q})^{o}$ and $P^{o}$ the time series in Fig. 8 a; $92 \%$ and $90 \%$, respectively.

Apparently, the enhancement of air mass flux convergence is an atmospheric response around this CSV $\left(\mathrm{HRF}_{2}^{3}\right)($ Fig. $8 \mathrm{~d})$ to the heat released by convection/ rainfall [Eqs. (6) and (8)] occurring during the second maximum intensity of this $\mathrm{CSV}\left(\mathrm{HRF}^{3}\right)$ (Fig. $8 \mathrm{c}$ ), as indicated by the center coincidence of $\chi_{\dot{Q}}$ and $\chi$ over this $\operatorname{CSV}\left(\mathrm{HRF}^{3}\right)$ center, and a large correlation coefficient between time series of $-\nabla \cdot \mathbf{Q}$ and $-\nabla^{2} \chi_{\dot{Q}}$. Obviously, the relay development for this Borneo CSV $\left(\mathrm{HRF}_{2}^{3}\right)$ by its second interaction with the SCS-type cold surge flow is an 


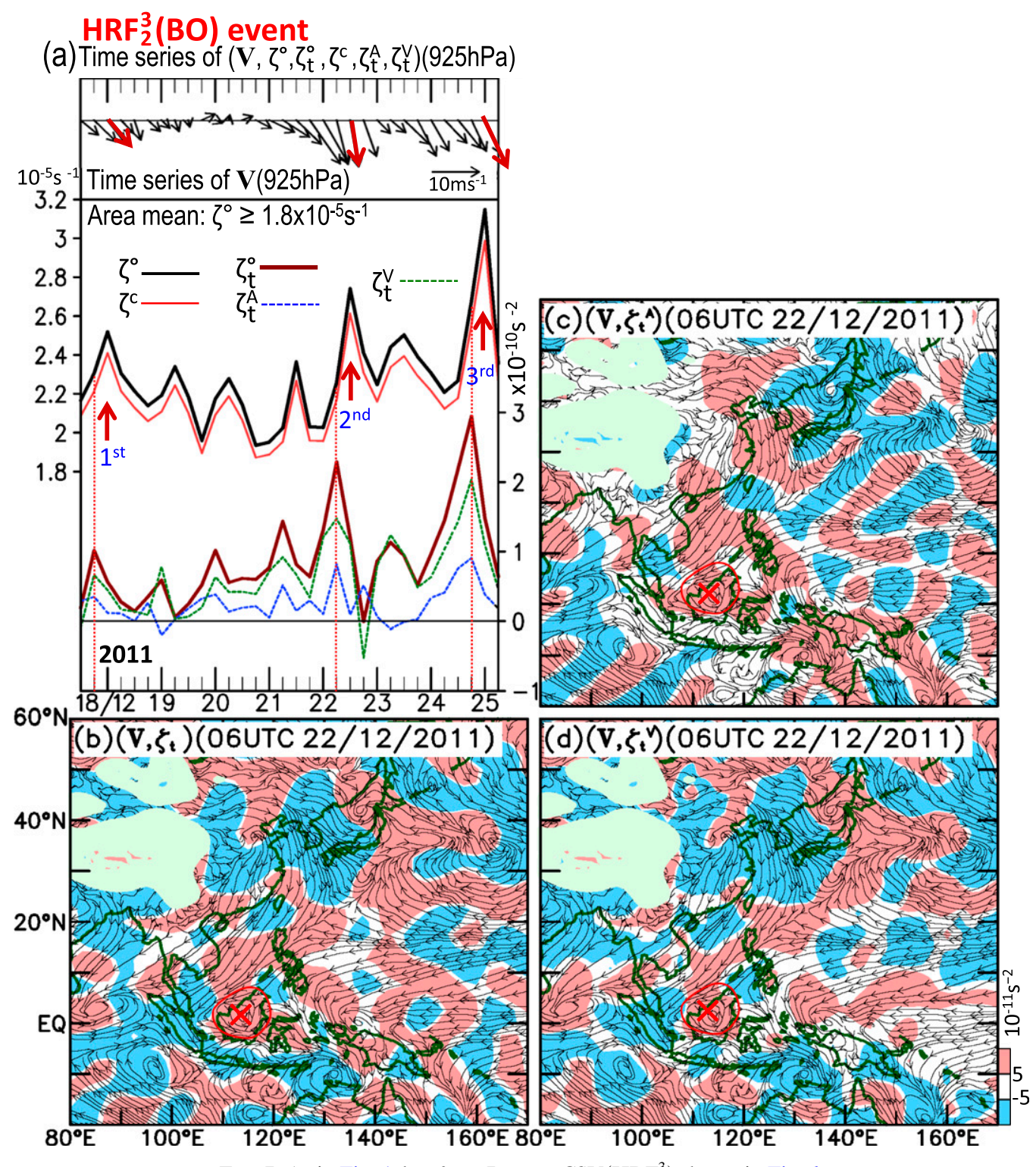

FIG. 7. As in Fig. 4, but for a Borneo $\mathrm{CSV}\left(\mathrm{HRF}_{2}^{3}\right)$ shown in Fig. 6.

important step to develop this $\mathrm{CSV}\left(\mathrm{HRF}_{2}^{3}\right)$ into a Borneo $\mathrm{HRF}_{2}^{3}$ event.

\section{Statistics for the HRF cyclone/event development through the multi-interaction process}

Over their life cycles, synoptic/dynamic development processes of two typical $\mathrm{HRF}_{2}^{3}$ cyclones/events through multi-interactions of their parent $\operatorname{CSV}\left(\mathrm{HRF}^{3}\right)$ with sequential cold surge flows and the intensified tropical trade easterlies linked to the occurrence of the northwestern Pacific explosive cyclone were illustrated in section 3a Philippine CSV $\left(\mathrm{HRF}_{2}^{3}\right)$ into a peninsular Malaysia $\mathrm{HRF}_{2}^{3}$ cyclone/event and a Borneo $\mathrm{CSV}\left(\mathrm{HRF}_{2}^{3}\right)$ into an in situ $\mathrm{HRF}_{2}^{3}$ cyclone/event. The $\zeta^{\circ}(925 \mathrm{hPa})$ time series for these two $\mathrm{CSV}\left(\mathrm{HRF}_{2}^{3}\right)$ shown in Figs. 3a and 6a reveal that the specially amplified $\zeta^{\circ}(925 \mathrm{hPa})$ maxima continue to increase through interactions of these $\mathrm{CSV}\left(\mathrm{HRF}_{2}^{3}\right)$ with sequential cold surge flows across the South China Sea. Development of these $\mathrm{CSV}\left(\mathrm{HRF}_{2}^{3}\right)$ into their corresponding $\mathrm{HRF}_{2}^{3}$ cyclones/events leads to the following questions:

1) Developing into $\mathrm{HRF}_{m}^{3}$ cyclones/events, why should $44 \%$ of the parent Philippine and Borneo $\operatorname{CSV}\left(\mathrm{HRF}_{m}^{3}\right)$ undergo multi-interactions with sequential cold surge flows?

2) Can the $\mathrm{HRF}_{m}^{3}$ cyclones/events become more intense and produce more rainfall through triple maximum 
$\mathrm{HRF}_{2}^{3}$ (BO) event

(a) Time series of $\left(\mathbf{V}, \zeta^{\circ}, \zeta_{t}^{\circ}\right)(925 \mathrm{hPa}), \mathrm{P}^{\circ}$,

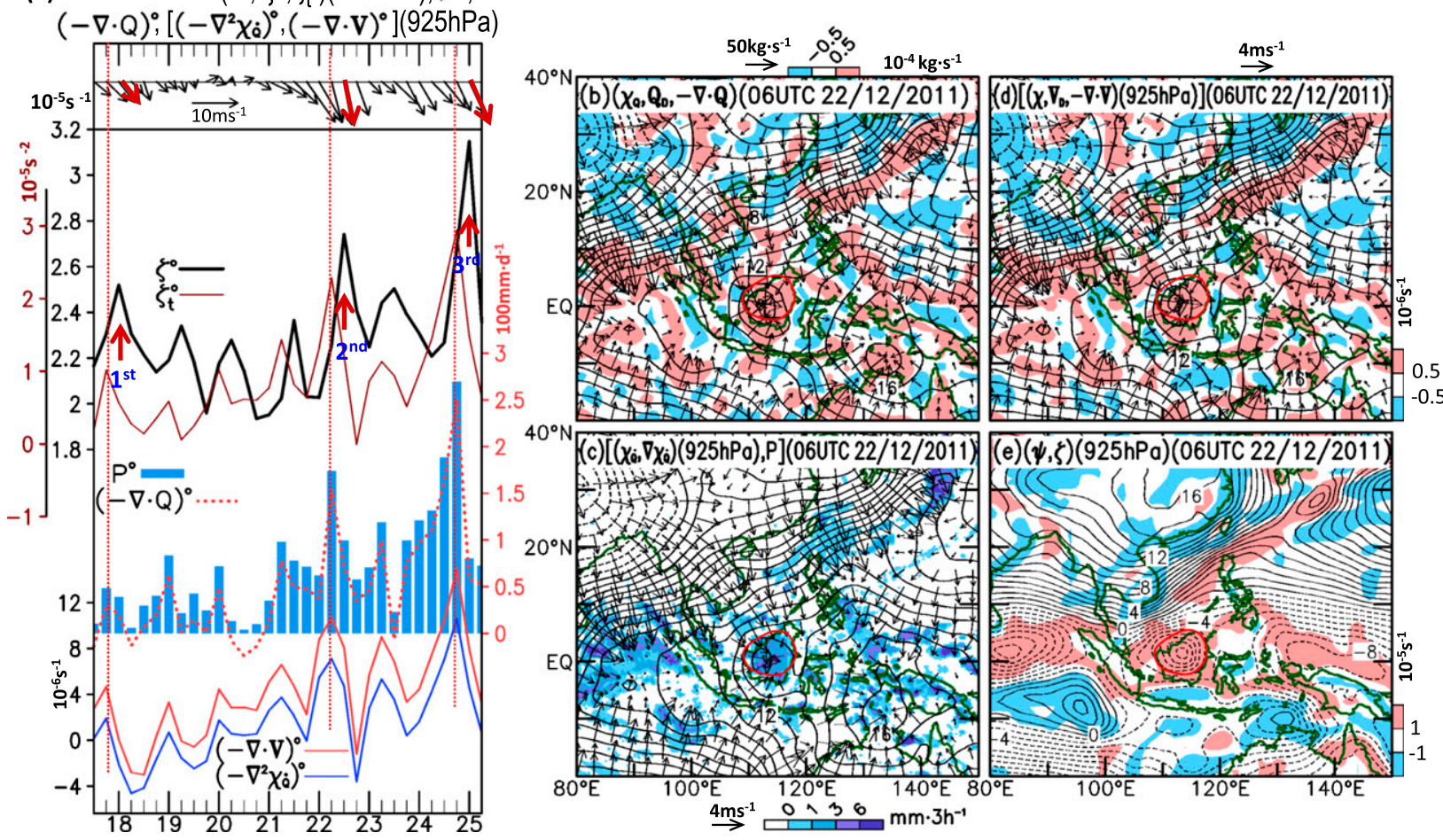

FIG. 8. As in Fig. 5, but for a Borneo $\mathrm{CSV}\left(\mathrm{HRF}_{2}^{3}\right)$ shown in Fig. 6.

$\zeta^{o}(925 \mathrm{hPa})$ than $\mathrm{HRF}_{m}^{2}$ cyclones/events through double maximum $\zeta^{\circ}(925 \mathrm{hPa})$ over the same rainfall centers?

3) What is the dynamic-hydrologic-thermodynamic role played by the second interaction of $\operatorname{CSV}\left(\mathrm{HRF}_{m}^{3}\right)$ with a cold surface flow in the development of $\mathrm{HRF}_{m}^{3}$ cyclones/events?

\section{a. Question 1}

The occurrence ratios of $\mathrm{HRF}_{m}^{3} / \mathrm{HRF}_{m}^{2}$ events on both sides of the South China Sea can be estimated with Fig. 1. West of the SCS, 47 of $83 \mathrm{HRF}_{m}^{n}$ events ( $57 \%$ ) occurred over the rainfall centers in central Vietnam and peninsular Malaysia. East of the SCS, 32 of $57 \mathrm{HRF}_{m}^{n}$ events $(56 \%)$ occurred over the rainfall centers of Borneo and Java. The western $\mathrm{HRF}_{m}^{3}$ cyclones/events developed from the remotely originated Philippines and Borneo $\operatorname{CSV}\left(\mathrm{HRF}_{m}^{3}\right)$, while the eastern $\mathrm{HRF}_{m}^{3}$ cyclones/events over Borneo and Java developed from the Borneo in situ $\operatorname{CSV}\left(\mathrm{HRF}_{m}^{3}\right)$. Regardless of their propagation distances, $\mathrm{HRF}_{m}^{3}$ events over the rainfall centers on both sides of the South China Sea developed from $\operatorname{CSV}\left(\mathrm{HRF}_{m}^{3}\right)$ with their life cycle $\geq 6$ days (indicated by vertical yellow stripes in Fig. 1). In contrast, a great majority of the $\mathrm{HRF}_{m}^{2}$ events developed from $\mathrm{CSV}_{\left(\mathrm{HRF}_{m}^{2}\right)}$ 4-6 days after these vortices formed, although some $(\sim 1 / 3)$ central Vietnam $\mathrm{HRF}_{2}^{2}$ events formed within 3-4 days. A majority of the $\operatorname{CSV}\left(\mathrm{HRF}_{m}^{3}\right)$ intensified by the second interaction with a cold surge flow occurred within 3-5 days after their parent $\operatorname{CSV}\left(\mathrm{HRF}_{m}^{3}\right)$ formed. The time needed for a $\operatorname{CSV}\left(\mathrm{HRF}_{m}^{n}\right)$ to form an $\mathrm{HRF}_{m}^{n}$ can be summarized by a clear stratification of the time frame (Fig. 9) from the $\operatorname{CSV}\left(\mathrm{HRF}_{m}^{n}\right)$ formation to the $\mathrm{HRF}_{m}^{n}$ occurrence as follows: 1) second maximum intensity of $\operatorname{CSV}\left(\mathrm{HRF}_{m}^{3}\right)<4$ days (3-5 days), 2) $\mathrm{HRF}_{1}^{2}$ events approximately 2 days (1-4 days), 3) $\mathrm{HRF}_{2}^{2}$ events approximately 5 days (4-6 days), 4) $\mathrm{HRF}_{2}^{2}$ events $\geq 6$ days (68.5 days), and 5) $\mathrm{HRF}_{3}^{3}$ events $\geq 8.5$ days (8.5-10 days).

Observed by Chen et al. (2004, their Fig. 3), the averaged occurrence frequency of the East Asian cold surge is about 4.5 (6) days during the warm (cold) ENSO phase. Based on these statistics, CSV(HRF) may develop in the two following ways:

1) For the first 3-5 days, this $\operatorname{CSV}\left(\mathrm{HRF}_{m}^{3}\right)$ may survive and interact with the next cold surge flow to develop the second maximum intensity for this vortex. For the next couple of days after this interaction, the intensified $\mathrm{CSV}\left(\mathrm{HRF}_{m}^{3}\right)$ may lead to the following three possible developments: (i) demise; (ii) maintainance of its interaction with the second aging cold surge flow 


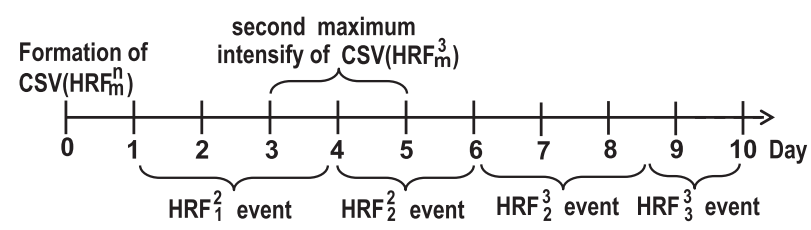

FIG. 9. Schematic diagram to illustrate the times used by a $\mathrm{CSV}\left(\mathrm{HRF}_{m}^{n}\right)$ from its formation location to reach the formation location of the corresponding $\mathrm{HRF}_{m}^{n}$ event and the location of sec-

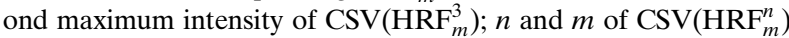
are the occurrence number of maximum $\zeta^{\circ}(925 \mathrm{hPa})$ and the interaction number of $\operatorname{CSV}\left(\mathrm{HRF}_{m}^{n}\right)$ with sequential cold surge flows for the $\operatorname{CSV}\left(\mathrm{HRF}_{m}^{n}\right)$ development into an $\mathrm{HRF}_{m}^{n}$ event.

until this $\operatorname{CSV}\left(\mathrm{HRF}_{2}^{3}\right)$ is intensified by the strengthened tropical trade easterlies related to the northwestern Pacific explosive cyclone, to form an $\mathrm{HRF}_{2}^{3}$ event, or (iii) interaction with the third cold surge flow and the intensified tropical trade easterlies, as the second possible development of $\mathrm{CSV}\left(\mathrm{HRF}_{2}^{3}\right)$, to form an $\mathrm{HRF}_{3}^{3}$ event. The third possible development only occurred four times over the 1979-2013 period.

2) For the next 4-6 days after its first interaction with a cold surge flow, the $\operatorname{CSV}\left(\mathrm{HRF}_{m}^{2}\right)$ may have the

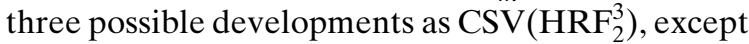
without a relay interaction with the second cold surge flow.

Based on our answer to question 1, it becomes clear the formation of either $\mathrm{HRF}_{m}^{2}$ or $\mathrm{HRF}_{m}^{3}$ event is determined by two basic factors: the time span of the parent $\operatorname{CSV}\left(\mathrm{HRF}_{m}^{n}\right)$ life cycles and the occurrence frequency of East Asian cold surge flows.

\section{b. Question 2}

The intensity of the parent $\operatorname{CSV}\left(\mathrm{HRF}_{m}^{n}\right)$ and their corresponding $\mathrm{HRF}_{m}^{n}$ cyclones/events may be measured by vorticity and rainfall. The vorticity, $\zeta^{\circ}(925 \mathrm{hPa})$ for all

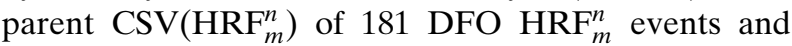
rainfall, and $P^{o}, 6 \mathrm{~h}$ prior to reaching the maximum intensity over the life cycles of these $\operatorname{CSV}\left(\mathrm{HRF}_{m}^{n}\right)$, are shown in Fig. 10.

\section{1) Vorticity}

Shown in Fig. 10a, six of nine HRF event groups develop from $\mathrm{CSV}\left(\mathrm{HRF}_{m}^{n}\right)$ through multi-interactions with sequential cold surge flows. Regardless of their future developments into either $\mathrm{HRF}_{m}^{2}$ or $\mathrm{HRF}_{m}^{3}$ events, intensities of their parent $\operatorname{CSV}\left(\mathrm{HRF}_{m}^{n}\right)$ are very close to each other, when they first form. Nevertheless, the intensity of $\mathrm{HRF}_{m}^{3}$ cyclones/events may increase $20 \%-40 \%$, while that for $\mathrm{HRF}_{m}^{2}$ cyclones/events is intensified by only $10 \%-25 \%$. Developing ultimately into $\mathrm{HRF}_{m}^{3}$ events, their parent $\mathrm{CSV}\left(\mathrm{HRF}_{m}^{n}\right)$ undergo a second intensification, which generally increases the second maximum intensity only $5 \%-10 \%$, smaller than the intensity for the $\mathrm{HRF}_{m}^{2}$ cyclone/event. Therefore, two important features of the $\mathrm{CSV}\left(\mathrm{HRF}_{m}^{n}\right)$ intensification for both $\mathrm{HRF}_{m}^{3}$ and $\mathrm{HRF}_{m}^{2}$ events should be recognized:

(i) As pointed out in our answer to question 1, it takes 1-2 more days for a $\operatorname{CSV}\left(\mathrm{HRF}_{m}^{2}\right)$ to form an $\mathrm{HRF}_{m}^{2}$ event than the time for a $\operatorname{CSV}\left(\mathrm{HRF}_{m}^{3}\right)$ to reach its second maximum intensity. The time period of 1-2 more days seems crucial for the $\mathrm{HRF}_{m}^{2}$ cyclone/ event to further intensify.

(ii) $\mathrm{The} \operatorname{CSV}\left(\mathrm{HRF}_{m}^{3}\right)$ may dissipate/demise, if there are no second interactions of these $\operatorname{CSV}\left(\mathrm{HRF}_{m}^{3}\right)$ with cold surge flows. Apparently, the relay interaction for $\operatorname{CSV}\left(\mathrm{HRF}_{m}^{3}\right)$ is an indispensible step in developing $\mathrm{HRF}_{m}^{3}$ cyclones/events.

\section{2) RAINFALL}

The rainfall amounts produced by $\mathrm{CSV}\left(\mathrm{HRF}_{m}^{n}\right) / \mathrm{HRF}_{m}^{n}$ events against their interaction frequency with cold surge flows for nine groups of $\mathrm{HRF}_{m}^{n}$ events are shown in Fig. 10b. Salient features of this figure may be highlighted as follows:

(i) $\mathrm{HRF}_{m}^{3}$ events produce more rainfall than $\mathrm{HRF}_{m}^{2}$ events. Rainfall produced by $\mathrm{HRF}_{m}^{3}$ cyclones/ events is about $400 \%-500 \%$ more than their parent $\mathrm{CSV}\left(\mathrm{HRF}_{\mathrm{m}}^{3}\right)$ produce, while $\mathrm{HRF}_{m}^{2}$ cyclones/events produced only about $300 \%-450 \%$ more. $\mathrm{HRF}_{m}^{2}$ cyclones/events produced about $40 \%-80 \%$ more rainfall than $\operatorname{CSV}\left(\mathrm{HRF}_{m}^{3}\right)$, when they reach their second rainfall maxima. Responses for CSV $\left(\mathrm{HRF}_{m}^{3}\right)$ in rainfall production over their life cycles and the relay interaction to develop $\mathrm{HRF}_{m}^{3}$ events resemble their vortex intensity change.

(ii) Despite the interaction frequency of $\operatorname{CSV}\left(\mathrm{HRF}_{m}^{n}\right)$ with cold surge flows, rainfall produced by $\mathrm{HRF}_{m}^{n}$ events north of $8^{\circ} \mathrm{N}$ (including central Vietnam and the Philippines) and the $\operatorname{HRF}_{m}^{n}(\mathrm{PM})$ events is larger than that produced south of $8^{\circ} \mathrm{N}$ (including peninsular Malaysia, Borneo, and Indonesia). This north-south differentiation in this HRF rainfall production may be attributed to two important elements of the southeastern Asia surface circulation: the island-chain and the near-equator troughs. The former trough facilitates the formation of the Philippine $\operatorname{CSV}\left(\mathrm{HRF}_{m}^{n}\right)$ and enhances rainfall produced by $\mathrm{HRF}_{m}^{n}$ events over the former group of rainfall centers. The near-equator trough across Borneo provides a favorable environment for the Borneo $\operatorname{CSV}\left(\mathrm{HRF}_{m}^{n}\right)$ formation, but it is not as efficient as the island-chain trough to 

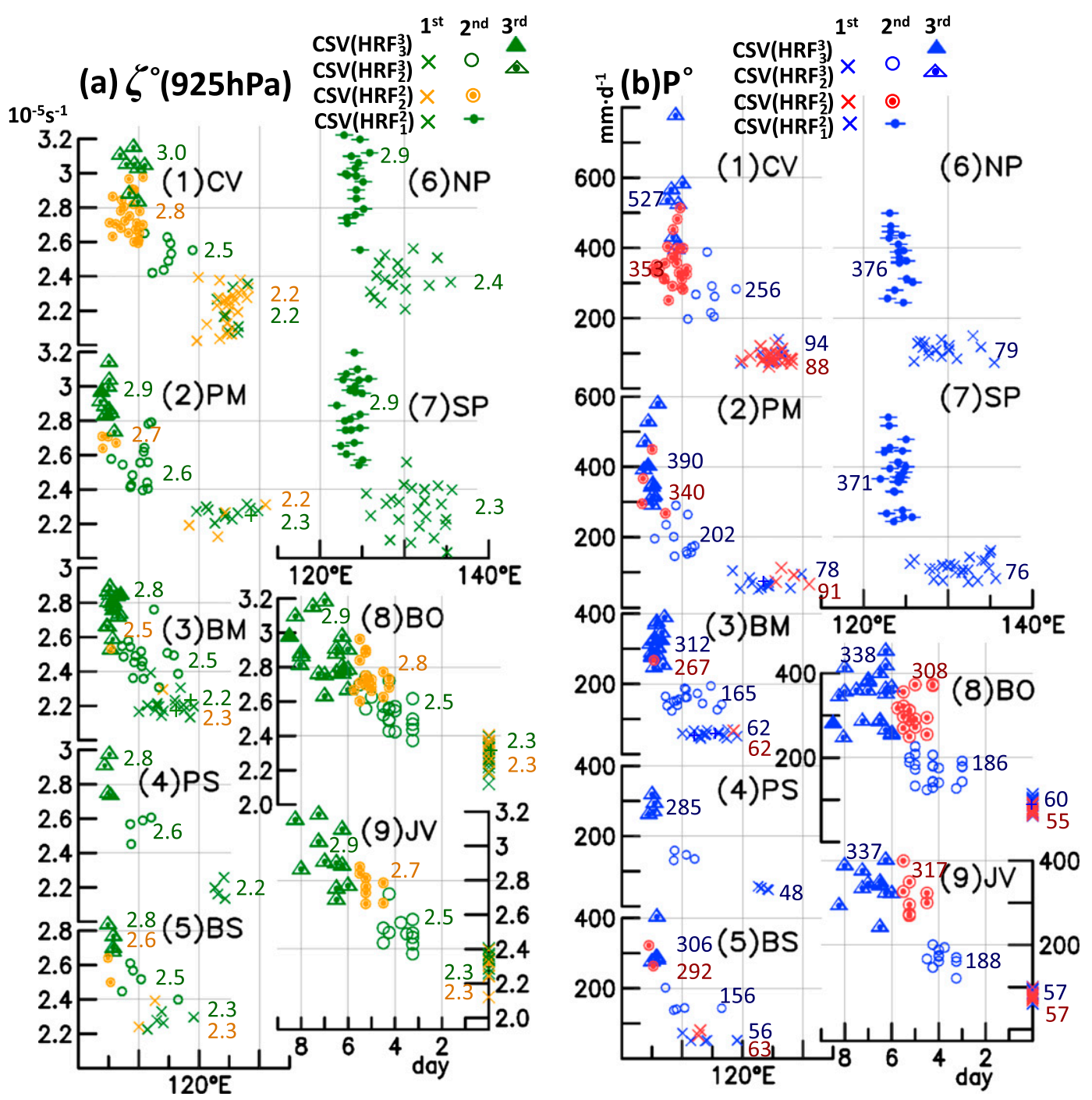

FIG. 10. (a) Scatter diagrams for $\zeta^{o}(925 \mathrm{hPa})$ (ordinate) vs longitude (abscissa) for nine groups of $\operatorname{CSV}\left(\mathrm{HRF}_{m}^{n}\right)$ $(n=2,3$ and $m=1,2,3)$ identified in Fig. 1 . The $\zeta^{o}(925 \mathrm{hPa})$ for $\operatorname{CSV}\left(\mathrm{HRF}_{m}^{3}\right)$ and $\operatorname{CSV}\left(\mathrm{HRF}_{1}^{2}\right)$ are denoted by different green symbols, while $\zeta^{\circ}(925 \mathrm{hPa})$ for $\operatorname{CSV}\left(\mathrm{HRF}_{2}^{2}\right)$ are marked by different gold symbols [see legend at the top right of (a)]. (b) Scatter diagrams for $P^{o}$ (ordinate) vs time (abscissa) for $\operatorname{CSV}\left(\mathrm{HRF}_{m}^{3}\right)$ and $\operatorname{CSV}\left(\mathrm{HRF}_{1}^{2}\right)$ marked by different blue symbols and for $\mathrm{CSV}\left(\mathrm{HRF}_{2}^{2}\right)$ are denoted by different red symbols [see legend at the top right of (b)].

facilitate the rainfall production over the latter group of heavy rainfall centers.

\section{c. Question 3}

The development of the second $\operatorname{CSV}\left(\mathrm{HRF}_{m}^{3}\right)$ maximum intensity for the typical peninsular Malaysia and Borneo $\mathrm{HRF}_{m}^{3}$ events through the dynamic, hydrologic and thermodynamic processes can be summarized as follows:

1) Illustrated by the vorticity budget in Eq. (1), the second $\operatorname{CSV}\left(\mathrm{HRF}^{3}\right)$ intensification is accomplished by two dynamic processes- $\zeta_{t}^{A}$ (vorticity distribution) and $\zeta_{t}^{V}$ (vortex stretching). Because $\zeta+f>0$ for a concerned CSV(HRF), this vortex can be intensified by $\zeta_{t}^{V} \sim-\boldsymbol{\nabla} \cdot \mathbf{V}>0$ through the convergence of air mass flux.

2) As expressed by Eq. (2), the second $\operatorname{CSV}\left(\mathrm{HRF}_{m}^{3}\right)$ maximum rainfall is increased/maintained by the convergence of water vapor flux [i.e., $-\boldsymbol{\nabla} \cdot \mathbf{Q}]$, driven by the convergence of the air mass flux indicated by Fig. 2.

3) The convergence of air mass flux in the low troposphere is part of the divergent circulation, which can be driven by diabatic heating, contributed partly by the heat for condensation through convection/ precipitation, $P$. According to Eq. (6), $\chi \sim \chi_{\dot{Q}}$ and $-\nabla \cdot \mathbf{V} \sim-\nabla \cdot \chi_{\dot{Q}}$. 


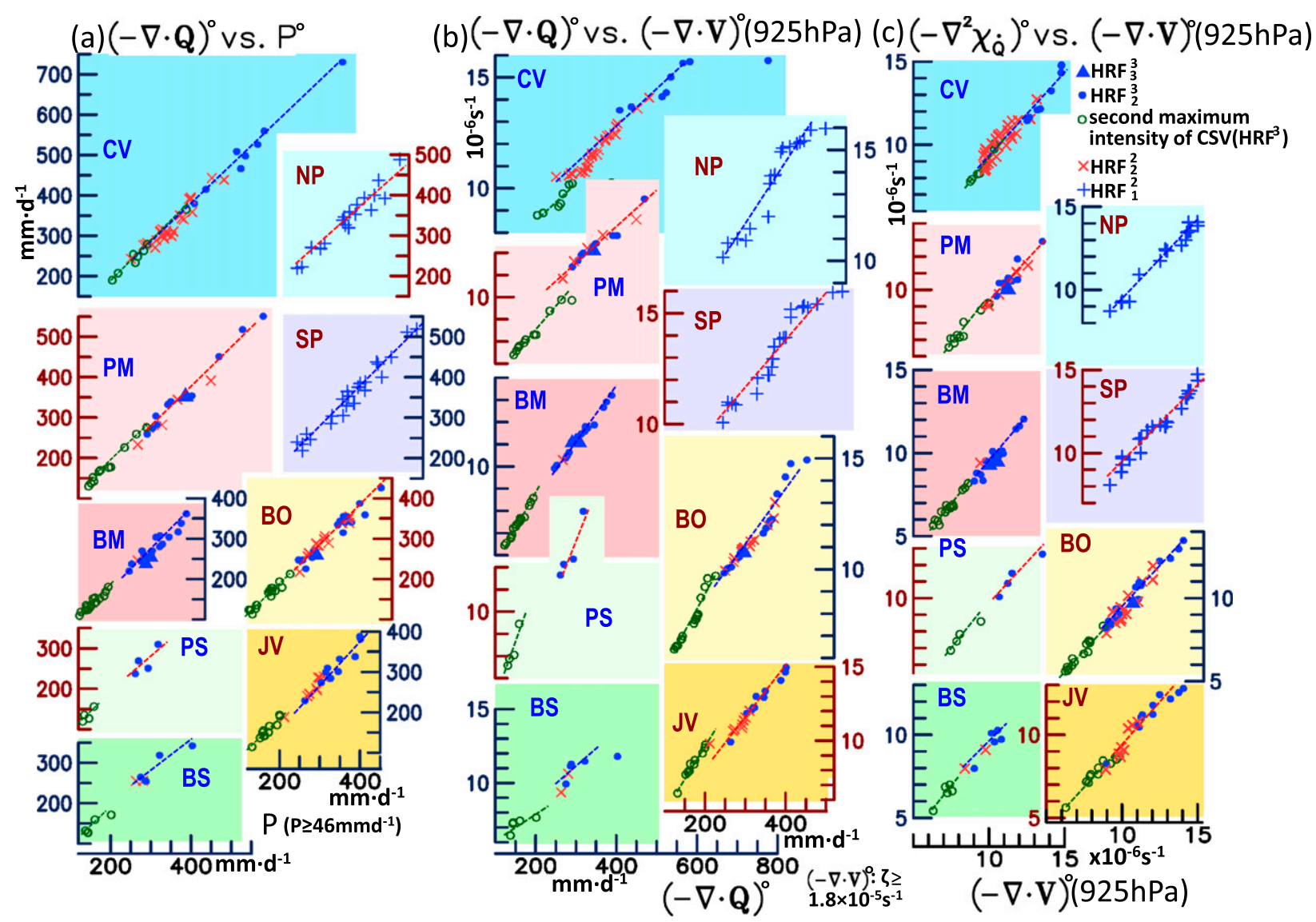

FIG. 11. Scatter diagrams of (a) $(-\nabla \cdot \mathbf{Q})^{o}$ vs $P$; (b) $(-\nabla \cdot \mathbf{Q})^{o}$ vs $(-\nabla \cdot \mathbf{V})^{o}(925 \mathrm{hPa})$; and $(\mathrm{c})\left(-\nabla^{2} \chi_{\dot{Q}}\right)^{o}$ vs $(-\nabla \cdot \mathbf{V})^{o}(925 \mathrm{hPa})$ for nine groups of $\mathrm{HRF}_{1}^{2}, \mathrm{HRF}_{2}^{2}, \mathrm{HRF}_{2}^{3}$, and $\mathrm{HRF}_{3}^{3}$ events are marked by a blue Greek cross, red cross, blue dot, and blue triangle, respectively. The

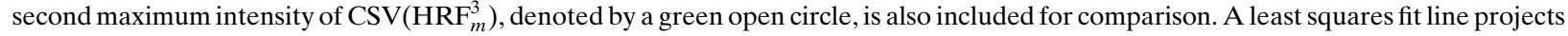
the relationship between each group of scatters.

The interrelationship among $-\boldsymbol{\nabla} \cdot \mathbf{V},-\boldsymbol{\nabla} \cdot \mathbf{Q}, P$, and $-\nabla \cdot \mathbf{V}_{\dot{Q}}$ to intensify the second $\mathrm{CSV}\left(\mathrm{HRF}_{m}^{3}\right)$ maximum intensity is illustrated in Fig. 2.

For all $\mathrm{HRF}_{m}^{3}$ and $\mathrm{HRF}_{m}^{2}$ events occurring over the same rainfall center, the three budgets $6 \mathrm{~h}$ prior to the $\mathrm{CSV}(\mathrm{HRF})$ necessary to form the $\mathrm{HRF}_{m}^{3} / \mathrm{HRF}_{m}^{2}$ events are shown in Fig. 11 and characterized by the follow salient features:

1) For both $\mathrm{HRF}_{m}^{3}$ and $\mathrm{HRF}_{m}^{2}$ events, the linear relationship between two variables shown in Fig. 2 emerges from all groups.

2) Before the formation of $\mathrm{HRF}_{m}^{3}$ events, the linear relationships between two variables also appears six hours before the second maximum intensity of its parent $\mathrm{CSV}\left(\mathrm{HRF}_{m}^{3}\right)$. The only exception for these linear relationships is all concerned variables are smaller in their magnitudes than both $\mathrm{HRF}_{m}^{3}$ and $\mathrm{HRF}_{m}^{2}$ events.

Results in Fig. 11 reveal two important implications:
1) The dynamical, hydrological, and thermodynamical processes in developing the second intensification of $\operatorname{CSV}\left(\mathrm{HRF}_{m}^{3}\right)$ resemble those involved with the development of $\mathrm{HRF}_{m}^{3}$ and $\mathrm{HRF}_{m}^{2}$ events. Despite the fact the second interaction of the $\operatorname{CSV}\left(\mathrm{HRF}_{m}^{3}\right)$ is unable to develop into an $\mathrm{HRF}_{m}^{3}$ event, this interaction plays a relay role crucial to develop $\mathrm{HRF}_{m}^{3}$ events.

2) Every process involved in the development of $\mathrm{HRF}_{m}^{2}$ events is quantitatively larger/stronger than that for developing the $\operatorname{CSV}\left(\mathrm{HRF}_{m}^{3}\right)$ second intensification. The development/intensification of $\mathrm{HRF}_{m}^{3}$ events cannot be achieved without the second intensification.

\section{Requirements for the HRF cyclone/event formation}

Two basic requirements needed for the formation of HRF cyclones/events in central Vietnam (Chen et al. 2012a,b) and Malaysia (Chen et al. 2013a,b), including peninsular Malaysia and Borneo are the following: 


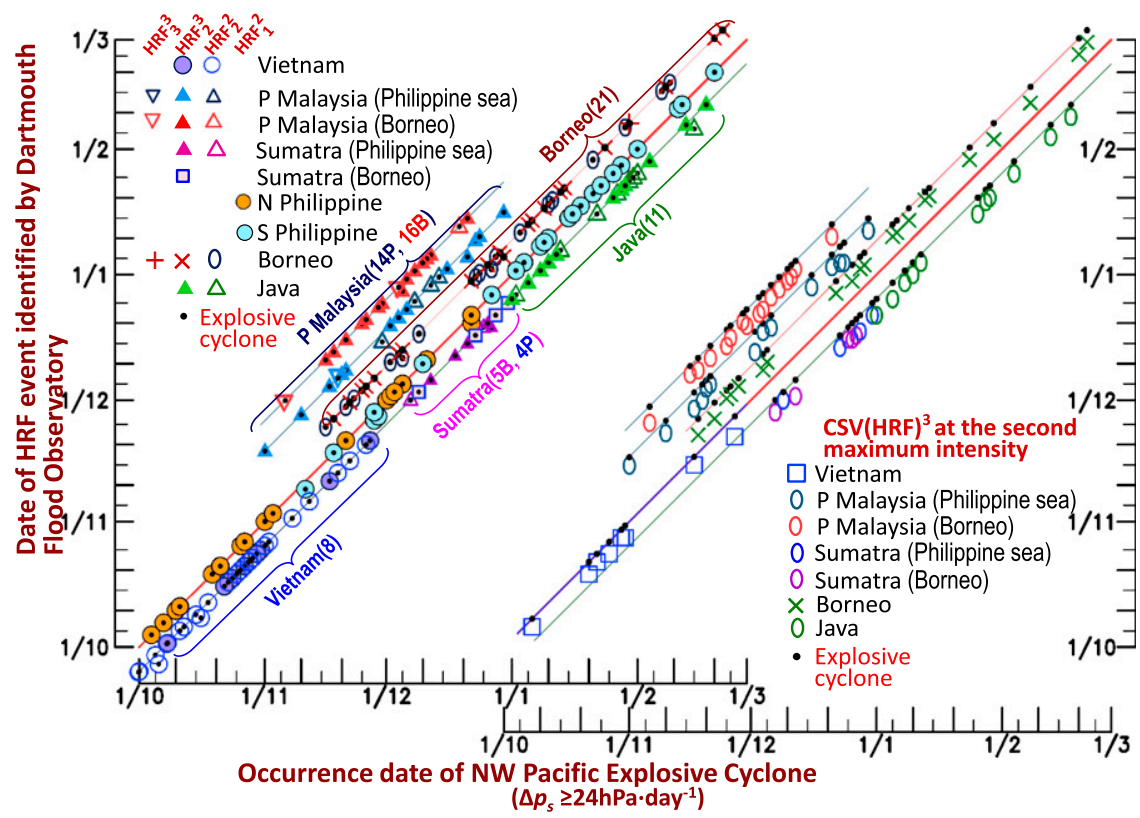

FIG. 12. (left) A scatter diagram for the synchronization occurrence dates of all DFO $\mathrm{HRF}_{m}^{n}$ events (abscissa) and the northwestern Pacific explosive cyclone (ordinate) during the time period of October-February over 1979-2012 for nine groups of $\mathrm{HRF}_{m}^{n}$ events indicated by different symbols in the top-left corner. (right) A scatter diagram for the dates of $\operatorname{CSV}\left(\mathrm{HRF}_{m}^{3}\right)$ reaching the second maximum intensity (abscissa) vs the dates of the northwestern Pacific explosive cyclone (ordinate) close to the former event. Symbols for different groups of $\operatorname{CSV}\left(\mathrm{HRF}_{m}^{3}\right)$ at their second maximum intensity are represented by different color symbols at the bottom-right corner.

1) Occurrence synchronization for formations of the HRF event and the northwestern Pacific explosive cyclone.

2) Occurrence simultaneity of maximum speeds in three synoptic elements: (i) easterlies of the HRF cyclone/ event, (ii) tropical trade easterlies of the North Pacific subtropical anticyclone, and (iii) westerlies of the northwestern Pacific explosive cyclone.

Requirement 1 for this $\operatorname{HRF}_{m}^{n}$ event formation has an important synoptic implication for the midlatitude-tropic interactions through the East Asian cold surge flow and the open ocean cold air outbreak flow in the North Pacific. These interactions are realized through intensification of the tropical trade easterlies by the open ocean cold air outbreak flow to the tropical Pacific and the merger of tropical trade easterlies with the East Asian cold surge flow to facilitate the $\mathrm{HRF}_{m}^{n}$ formation. The HRF event can be formed through the $\operatorname{CSV}\left(\operatorname{HRF}_{m}^{n}\right)$ multi-interactions with sequential cold surge flows. Can these $\mathrm{HRF}_{m}^{2}$ and $\mathrm{HRF}_{m}^{3}$ events occur when the westerly flow of the northwestern Pacific explosive cyclone, the tropical trade easterlies of the North Pacific subtropical anticyclone, and the easterly flow of the $\mathrm{HRF}_{m}^{n}$ cyclone reach their maximum speeds simultaneously to meet requirement 2 ?

Shown in Fig. 2 of Part I, 181 HRF events developed from their parent $\operatorname{CSV}\left(\mathrm{HRF}_{m}^{n}\right)$ formed in the Philippine vicinity and Borneo. As can be inferred from trajectories of these $\operatorname{CSV}\left(\mathrm{HRF}_{m}^{n}\right)$ originating in these two regions to seven rainfall centers and the environment flow patterns in different seasons, the steering mechanisms of parent $\mathrm{CSV}\left(\mathrm{HRF}_{m}^{n}\right)$ to different rainfall centers may be different. The following questions are raised by this observation:

1) Can the two basic requirements for the formation of $\mathrm{HRF}_{m}^{n}$ events in central Vietnam and Malaysia be met by all $\mathrm{HRF}_{m}^{n}$ events around the South China Sea?

2) The development of $\mathrm{HRF}_{m}^{3}$ events always go through a second interaction of their parent CSV(HRF) with cold surge flow to attain their second maximum intensity. Why does not the $\operatorname{CSV}\left(\mathrm{HRF}_{m}^{3}\right)$ at this stage develop into an $\mathrm{HRF}_{m}^{3}$ event?

\section{a. Question 1}

\section{1) OCCURRENCE SYNCHRONIZATION OF HRF EVENT AND EXPLOSIVE CYCLONE}

Following Chen et al. (2012a, 2013a), the scatter diagram of the occurrence dates (ordinate) for all $181 \mathrm{HRF}$ events versus formation dates (abscissa) of the corresponding northwestern Pacific explosive cyclones is shown in the left of Fig. 12. All HRF ${ }_{m}^{n}$ events are distinguished by different symbols in the top-left corner. Regardless of the 
parent $\operatorname{CSV}\left(\mathrm{HRF}_{m}^{n}\right)$ interaction frequency with cold surge flows, the occurrence synchronization with explosive cyclones holds for about $92 \%$ of the $\mathrm{HRF}_{m}^{n}$ events. Only 14 $\mathrm{HRF}_{m}^{n}$ events $(\sim 8 \%)$ are 1-2 days behind the formation dates of the corresponding cyclones. These $14 \mathrm{HRF}_{m}^{n}$ events are randomly distributed in different groups of $\mathrm{HRF}_{m}^{n}$ events.

All $79 \mathrm{HRF}_{m}^{3}$ events develop through their parent $\operatorname{CSV}\left(\mathrm{HRF}_{m}^{n}\right)$ multi-interactions with sequential cold surge flows. For the second interaction of a parent $\operatorname{CSV}\left(\mathrm{HRF}_{2}^{3}\right)$ with a cold surge flow, a relay intensification of this vortex is needed for it to become an $\mathrm{HRF}_{m}^{3}$ event. However, the second interaction of this $\operatorname{CSV}\left(\mathrm{HRF}_{m}^{3}\right)$ does not suffice its development into an $\mathrm{HRF}_{2}^{2}$ event. Shown in the right scatter diagram of Fig. 12, the second intensification of the $\operatorname{CSV}\left(\mathrm{HRF}_{m}^{3}\right)$ to reach its second maximum intensity is 2-3 days prior to the formation of the northwestern Pacific explosive cyclone. Apparently, the $\mathrm{CSV}\left(\mathrm{HRF}_{m}^{3}\right)$ second peak intensity is not synchronous with the northwestern Pacific explosive cyclone formation. The lack of this occurrence synchronization does not allow the basin-scale circulation over the North Pacific to develop a favorable synoptic condition for this $\mathrm{CSV}\left(\mathrm{HRF}_{m}^{3}\right)$ to form an $\mathrm{HRF}_{2}^{2}$ event.

Shown in Fig. 13, the winter [December-February (DJF)]-mean cyclonic shear flow along the northwestern part of the cyclonic cells centered at southwestern Borneo where the near-equator trough penetrates, provides a positive vorticity zone. Additionally, indicated by the 850 -hPa streamfunction [ $\psi(850 \mathrm{hPa})]$ distribution, a northsouth-oriented shallow/weak trough line exists in the South China Sea. These two special seasonal-mean lowtropospheric circulation elements develop a favorable environment for the second intensification of $\mathrm{CSV}\left(\mathrm{HRF}_{m}^{3}\right)$ across the South China Sea. The location distribution of the second maximum intensity of $\operatorname{CSV}\left(\mathrm{HRF}_{m}^{3}\right)$ in Fig. 13 confirms this inference.

\section{2) OCCURRENCE SIMULTANEITY OF MAXIMUM SPEEDS BY THREE SYNOPTIC ELEMENTS}

For convenience, let $u_{\mathrm{PEC}}, u_{\mathrm{TTW}}$, and $u_{\mathrm{HRF}}$ represent, respectively, the westerlies of the northwestern Pacific explosive cyclone, the tropical trade easterlies of the North Pacific subtropical anticyclone, and the easterlies of the $\mathrm{HRF}$ cyclone/event. Using $18 \mathrm{HRF}_{m}^{n}$ events for nine rainfall centers as examples, the $u_{\mathrm{PEC}}(850 \mathrm{hPa})$ westerly time series and the $u_{\mathrm{TTW}}(850 \mathrm{hPa})$ easterly time series at the longitude location of maximum $u_{\mathrm{PEC}}(850 \mathrm{hPa})$ westerlies and the $u_{\mathrm{HRF}}(850 \mathrm{hPa})$ easterly time series at the longitude location of maximum $u_{\mathrm{HRF}}(850 \mathrm{hPa})$ easterlies for $\mathrm{HRF}_{m}^{n}$ events are displayed in Fig. 14a. The formation dates of explosive cyclones and HRF cyclones/events coincide with the maximum $u_{\mathrm{TTW}}(850 \mathrm{hPa})$ date and are

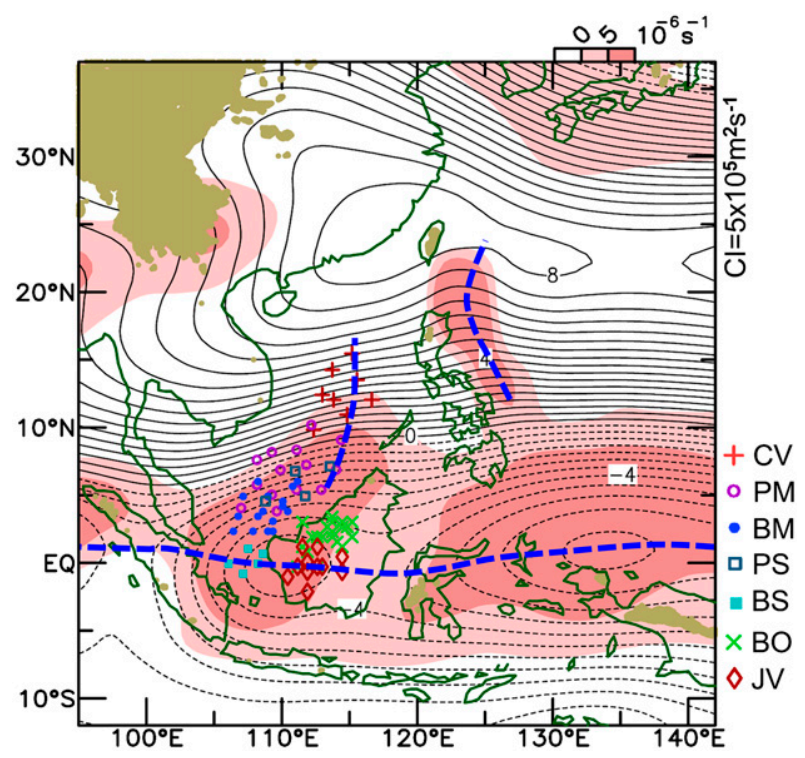

FIG. 13. The winter (DJF)-mean $\psi(850 \mathrm{hPa})$ chart superimposed with $\zeta(850 \mathrm{hPa})$ (pink shading) and locations of the $\mathrm{CSV}\left(\mathrm{HRF}_{m}^{3}\right)$ second maximum intensity (marked with different symbols on the bottom right-hand side of the figure), the island-chain trough, the South China Sea trough, and the near-equator trough (Johnson and Houze 1987; Johnson 2005). The troughs are marked by dashed blue lines.

confirmed by the occurrence simultaneity of maximum speeds for $u_{\mathrm{PEC}}$ westerlies, and for easterlies of $u_{\mathrm{TTW}}$ and $u_{\mathrm{HRF}}$, when the corresponding $\mathrm{HRF}_{m}^{n}$ event occurs. To verify the occurrence simultaneity of these three zonal speeds for all cases of $\operatorname{HRF}_{m}^{n}$ events, two different approaches are adopted to perform this verification:

(i) A manual approach: The three maximum zonal speeds $\left(u_{\mathrm{PEC}}, u_{\mathrm{TTW}}\right.$, and $\left.u_{\mathrm{HRF}}\right)$ of all HRF events are connected to check whether these three zonal speeds reach a maximum simultaneously. Occurrences of $14 \mathrm{HRF}_{m}^{n}$ events that do not synchronize with those of explosive cyclones are confirmed by this approach.

(ii) Correlation coefficient approach: Using the three correlation coefficients $\sigma\left(u_{\mathrm{HRF}}, u_{\mathrm{PEC}}\right), \sigma\left(u_{\mathrm{HRF}}, u_{\mathrm{TTW}}\right)$, and $\sigma\left(u_{\mathrm{HRF}}, u_{\mathrm{TTW}}\right)^{1}$ as three axes, the threedimensional scatter diagrams for these three correla-

\footnotetext{
${ }^{1}$ When $u_{\mathrm{HRF}}, u_{\mathrm{PEC}}$, and $u_{\mathrm{TTW}}$ reach their maximum values on the date of the HRF event, they are given a value of 3 . If the value of any $u$ has its maximum at 1 (2) day(s) ahead of the related HRF event, this variable is given a value of $2(1)$, and if the maximum is 1 (2) day(s) behind the HRF event, the value is 4 (5). The time series for these numerical values is used to generate correlation coefficients between two time series. The correlation coefficient value of 1 should be obtained, if two time series have only values of 3 . If these two time series have values other than 3, the correlation coefficient value should be smaller than 1 .
} 
(a)HRF event
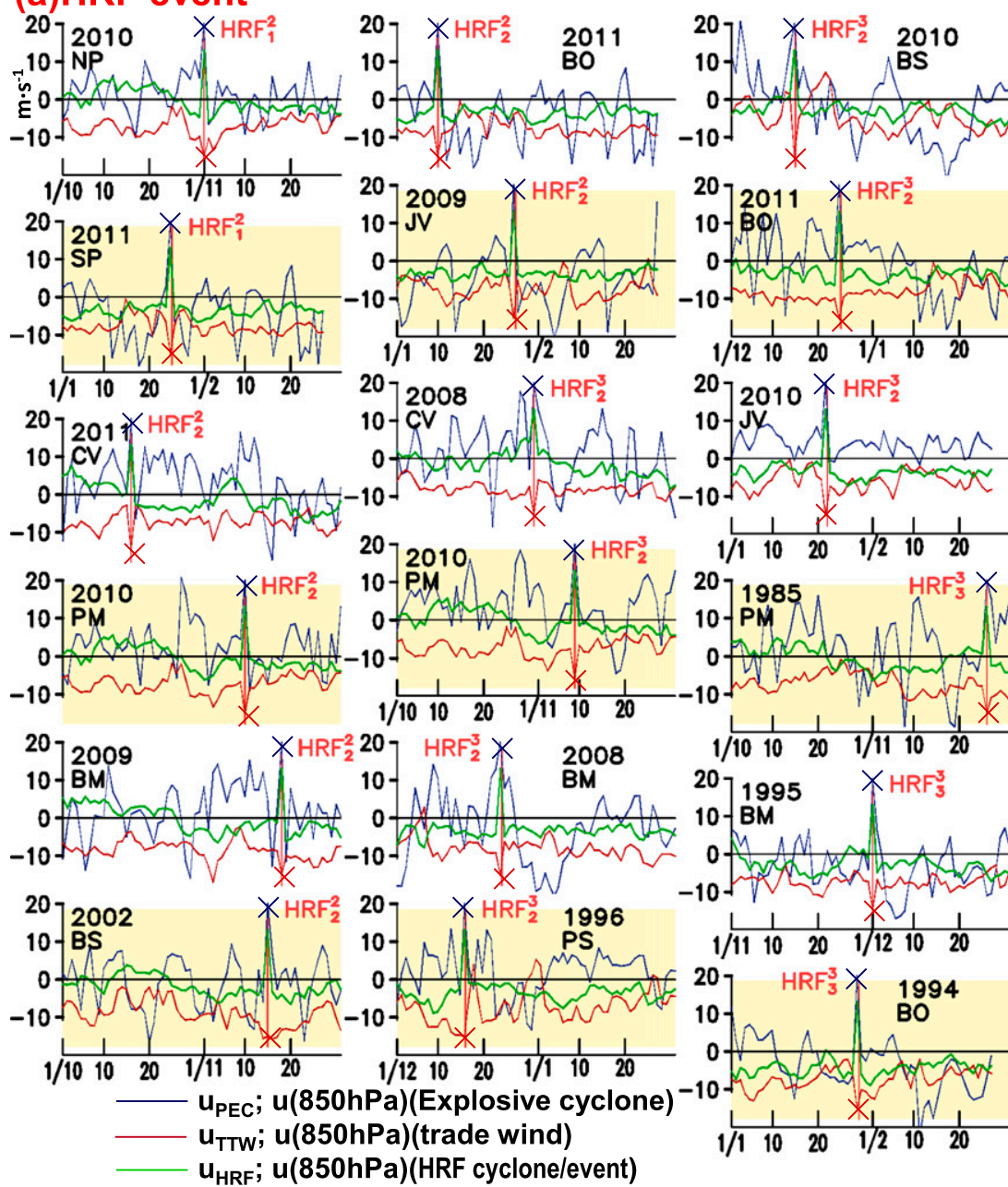

$\underset{\times}{\times}\}$ : formation date of $\left\{\begin{array}{l}\text { explosive cyclones } \\ \mathrm{HRF} \text { cyclones }\end{array}\right.$
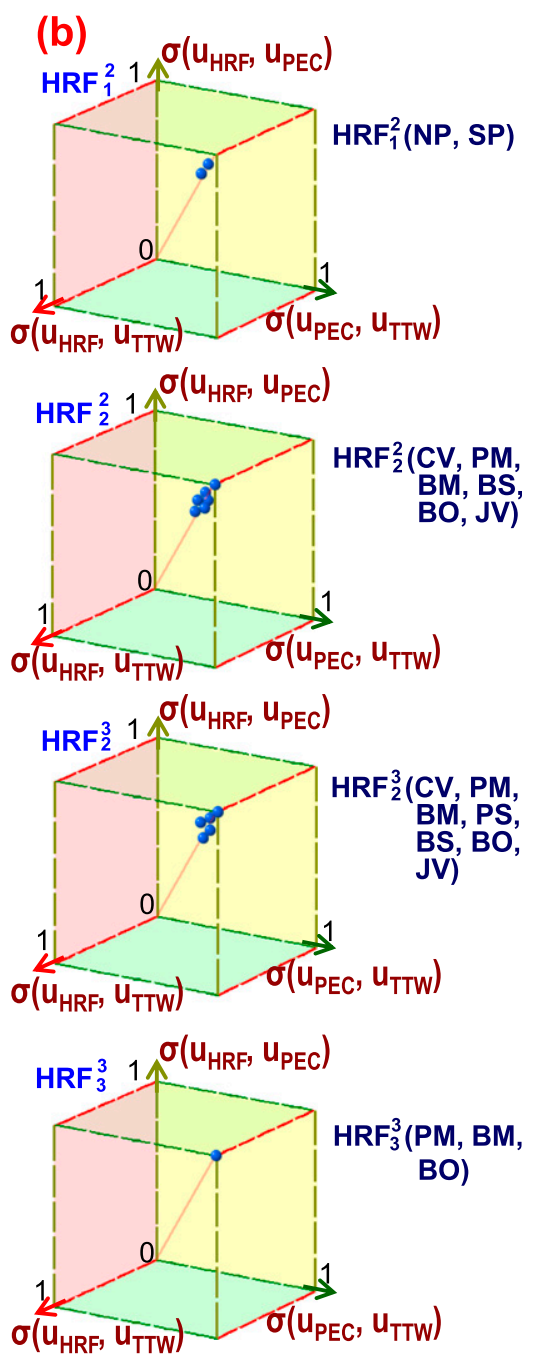

FIG. 14. (a) Time series for $u(850 \mathrm{hPa})$ at the location of the maximum isotach for three synoptic systems: the southern rim of the northwestern Pacific explosive cyclone ( $u_{\mathrm{PEC}}$; dark blue line), the tropical trade easterlies ( $u_{\mathrm{TTW}}$; red line) corresponding to the location of $u_{\mathrm{PEC}}$, and north of the HRF cyclone ( $u_{\mathrm{HRF}}$; green line) for selected eighteen $\mathrm{HRF}_{m}^{n}$ events in nine rainfall centers. The occurrence dates for explosive cyclones and $\mathrm{HRF}_{m}^{n}$ cyclones/events are marked by red and dark blue crosses, respectively. (b) Three-dimensional scatter diagrams of correlation $\sigma\left(u_{\mathrm{HRF}}, u_{\mathrm{PEC}}\right), \sigma\left(u_{\mathrm{PEC}}, u_{\mathrm{TTW}}\right)$, and $\sigma\left(u_{\mathrm{HRF}}, u_{\mathrm{TTW}}\right)$ for nine groups of $\mathrm{HRF}_{m}^{n}$ events; one blue dot represents a group. These $\mathrm{HRF}_{m}^{n}$ events are classified into four groups, $\mathrm{HRF}_{1}^{2}, \mathrm{HRF}_{2}^{2}, \mathrm{HRF}_{2}^{3}$, and $\mathrm{HRF}_{3}^{3}$, and projected on the three three-dimensional scatter diagrams.

tion coefficients for four types of $\mathrm{HRF}_{m}^{n}$ events shown in Fig. 14b vary between 1 and 0.9 .

The occurrence simultaneity for the maximum easterlies of $u_{\mathrm{HRF}}$ and $u_{\mathrm{TTW}}$, and westerlies of $u_{\mathrm{PEC}}$ is met by a great majority $(\geq 92 \%)$ of HRF events, regardless of the interaction frequency of their parent CSV(HRF) with cold surge flows.

\section{b. Question 2}

Because $79 \mathrm{HRF}_{m}^{3}$ events are identified, one may question whether the basic requirements for the formation of $\mathrm{HRF}_{m}^{n}$ events around the South China Sea can be met by the intensification of $\mathrm{CSV}\left(\mathrm{HRF}_{m}^{3}\right)$ to reach their second maximum intensity (prior to formation of the $\mathrm{HRF}_{m}^{3}$ event). It was shown in Fig. 12 that no single northwestern Pacific explosive cyclone occurrence synchronizes with the occurrence of the $\operatorname{CSV}\left(\mathrm{HRF}_{m}^{3}\right)$ second maximum intensity. The basin-scale synoptic environment favorable for the $\mathrm{HRF}_{m}^{n}$ event formation is developed by the occurrence synchronization of the $\mathrm{HRF}_{m}^{n}$ event and the northwestern Pacific explosive cyclone. The occurrence simultaneity of maximum easterlies of $u_{\mathrm{HRF}}$ and $u_{\mathrm{TTW}}$, and westerlies of $u_{\mathrm{PEC}}$ cannot be met by the $\operatorname{CSV}\left(\mathrm{HRF}_{m}^{3}\right)$, when it reaches its second maximum 
peak intensity. The favorable basin-scale synoptic environment for $\operatorname{CSV}\left(\mathrm{HRF}_{m}^{3}\right)$ at its second maximum intensity to form an $\mathrm{HRF}_{m}^{3}$ event does not develop. Nevertheless, the intensification of a $\operatorname{CSV}\left(\mathrm{HRF}_{m}^{3}\right)$ to reach its second maximum peak intensity is an indispensible process for the development of a $\operatorname{CSV}\left(\mathrm{HRF}_{m}^{3}\right)$ into an $\mathrm{HRF}_{m}^{3}$ event, but not possibly to directly develop into an $\mathrm{HRF}_{m}^{3}$ cyclone/event.

\section{Summary and concluding remarks}

Shown in Fig. 1, the life cycle of a $\operatorname{CSV}\left(\mathrm{HRF}_{m}^{n}\right)$, the time from its formation to the occurrence of the corresponding $\mathrm{HRF}_{m}^{n}$ event, may be 1-4 days over the Philippine rainfall center and 3-9 days for other rainfall centers (including central Vietnam, peninsular Malaysia, southeastern Sumatra, Java, and Borneo) around the South China Sea. The occurrence frequency of the East Asian cold surge is about 4.5 (6) days on the average during the warm (cold) ENSO phase (Chen et al. 2004). Thus, the development of $\operatorname{CSV}\left(\mathrm{HRF}_{m}^{n}\right)$ into $\mathrm{HRF}_{m}^{n}$ events should be achieved through their multi-interactions with cold surge flows, one to three times.

The 925-hPa vorticity averaged over the area around a $\operatorname{CSV}(\mathrm{HRF})$ with $\zeta \geq 1.8 \times 10^{-5} \mathrm{~s}^{-1}, \zeta^{o}(925 \mathrm{hPa})$, is used as an indicator of the CSV(HRF) intensity. Tracking CSV(HRF) for 181 DFO HRF events during the 1979-2012 period, the $\zeta^{\circ}(925 \mathrm{hPa})$ time series of $\operatorname{CSV}\left(\mathrm{HRF}_{m}^{n}\right)$ over their life cycles are prepared with the Lagrangian approach. The peak intensity of CSV $\left(\mathrm{HRF}_{m}^{n}\right)$ interacting with the cold surge flow is well reflected by the detrended peak $\zeta^{\circ}(925 \mathrm{hPa})$ value $\geq$ one standard deviation of the detrended $\zeta^{\circ}(925 \mathrm{hPa})$ time series. Based on this approach, two groups of $181 \mathrm{HRF}$ events are categorized:

1) The $102 \mathrm{HRF}_{m}^{2}$ events develop from two different processes: (i) The $41 \mathrm{HRF}_{1}^{2}$ events, developed from the Philippine $\operatorname{CSV}\left(\mathrm{HRF}_{1}^{2}\right)$, interact with the same PHS-type cold surge during (their) formations and formations of $\mathrm{HRF}_{1}^{2}$ events. (ii) The $61 \mathrm{HRF}_{2}^{2}$ events developed from $\operatorname{CSV}\left(\mathrm{HRF}_{2}^{2}\right)$, which form by the interactions of original perturbations with one cold surge and later evolve into $\mathrm{HRF}_{2}^{2}$ events by interacting with another sequential cold surge flow.

2) The $79 \mathrm{HRF}_{m}^{3}$ events developed from their parent $\mathrm{CSV}\left(\mathrm{HRF}_{m}^{3}\right)$ interacting with two or three sequential cold surge flows. The second peak intensity of a CSV $\left(\mathrm{HRF}_{m}^{3}\right)$ by its interaction with the second cold surge flow serves as a relay intensification of the $\operatorname{CSV}\left(\mathrm{HRF}_{m}^{3}\right)$ to form an $\mathrm{HRF}_{m}^{3}$ event.

The development of $\mathrm{HRF}_{m}^{2}$ involved interactions with the same or another cold surge flow, respectively, while the development of $\mathrm{HRF}_{m}^{3}$ is involved with two or three different cold surge flows in sequence. The reasons for $\mathrm{HRF}_{m}^{3}$ events to need one extra interaction with a cold surge flow are the following:

1) The life cycles for all $79 \mathrm{CSV}\left(\mathrm{HRF}_{m}^{3}\right)$ to form $\mathrm{HRF}_{m}^{3}$ events are $\geq 6$ days, longer than the occurrence frequency of the East Asian cold surges.

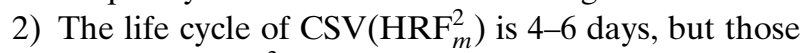
for $\mathrm{CSV}\left(\mathrm{HRF}_{m}^{3}\right)$ to reach its second maximum intensity is about $3-5$ days, shorter than $\operatorname{CSV}\left(\mathrm{HRF}_{m}^{2}\right)$ to form $\mathrm{HRF}_{m}^{2}$ events.

3) A shallow-weak surface trough along the northeastsouthwest axis of the South China Sea facilitates the

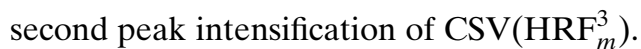

The basic difference in the development processes between $\mathrm{HRF}_{m}^{3}$ and $\mathrm{HRF}_{m}^{2}$ events lies with the former group, which has the relay interaction of $\operatorname{CSV}\left(\mathrm{HRF}_{m}^{3}\right)$ with the second sequential cold surge flow.

The roles played by the second maximum intensity of $\mathrm{CSV}\left(\mathrm{HRF}_{m}^{3}\right)$ to develop $\mathrm{HRF}_{m}^{3}$ events are as follows:

1) The time (3-5 days) for a $\operatorname{CSV}\left(\mathrm{HRF}_{m}^{3}\right)$ to reach its second maximum peak intensity is shorter than that for the $\mathrm{CSV}\left(\mathrm{HRF}_{2}^{2}\right)$ to form an $\mathrm{HRF}_{2}^{2}$ event. Thus, the westward-propagating $\operatorname{CSV}\left(\mathrm{HRF}_{m}^{3}\right)$ attain their second maximum peak intensity in the middle of the South China Sea.

2) $\operatorname{CSV}\left(\mathrm{HRF}_{m}^{3}\right)$, at its second peak intensity, cannot satisfy the two occurrence requirements for $\mathrm{HRF}_{2}^{3}$ events: (i) synchronization of the $\operatorname{CSV}\left(\mathrm{HRF}_{m}^{3}\right)$ second peak intensity with the formation of the northwestern Pacific explosive cyclone, and (ii) occurrence simultaneity of maximum speeds by the explosive cyclone westerlies, tropical trade easterlies of the North Pacific anticyclone, and easterlies of the $\operatorname{CSV}\left(\mathrm{HRF}_{2}^{3}\right)$ at its second peak intensity. Thus, the basin-scale synoptic environment cannot develop a favorable environment to allow this $\operatorname{CSV}\left(\mathrm{HRF}_{2}^{3}\right)$ at its second peak intensity develop into an $\mathrm{HRF}_{2}^{3}$ event.

3) The second maximum intensity of the $\operatorname{CSV}\left(\mathrm{HRF}_{2}^{3}\right)$ enables itself to evolve into an $\mathrm{HRF}_{2}^{3}$ cycle/event whose intensity and rainfall are generally larger than that for the $\mathrm{HRF}_{2}^{2}$ cyclone/event. Thus, the relay interaction of the $\operatorname{CSV}\left(\mathrm{HRF}_{2}^{3}\right)$ is an indispensible step for this vortex to develop into an $\mathrm{HRF}_{2}^{3}$ event.

The identification for the two groups of $\mathrm{HRF}_{m}^{n}$ events in their development reveals several unique features of these $\mathrm{HRF}_{m}^{n}$ cyclones/events:

1) The development of $\mathrm{HRF}_{1}^{2}$ events over the northern and southern Philippines are involved only by the interaction of the Philippine $\operatorname{CSV}\left(\mathrm{HRF}_{1}^{2}\right)$ with one 
PHS-type cold surge flow and the two aforementioned requirements of the basin-scale environment for the formation/occurrence of HRF. The development of this $\operatorname{CSV}\left(\mathrm{HRF}_{1}^{2}\right)$ has not attracted any attention, yet. Further research efforts are needed to explore the development mechanism of the Philippine $\mathrm{HRF}_{1}^{2}$ event.

2) Most of the super-HRF (with maximum rainfall $\left.\geq 500 \mathrm{~mm} \mathrm{day}^{-1}\right)$ events $(\sim 75 \%)$ in Vietnam are $\mathrm{HRF}_{2}^{3}$ events. Some super-HRF events in Vietnam are $\mathrm{HRF}_{2}^{2}$ events, but the population ratio is much lower ( $\sim 15 \%$ of $\mathrm{HRF}_{2}^{2}$ events).

3) The development of synoptic disturbances through three consecutive forcings, as the multi-interactions with sequential cold surge flows, has not been identified in any region of the globe.

These unique features of $\mathrm{CSV}\left(\mathrm{HRF}_{m}^{n}\right)$ development into $\mathrm{HRF}_{m}^{n}$ events also lead us to face new research challenges:

1) The development of the Philippine $\mathrm{HRF}_{1}^{2}$ event is very different from the other two groups of HRF events. How do the Philippine $\mathrm{HRF}_{1}^{2}$ events develop from the Philippine $\operatorname{CSV}\left(\mathrm{HRF}_{1}^{2}\right)$ through their interaction with only one PHS-type cold surge flow?

2) The development of the $\mathrm{HRF}_{m}^{n}$ event around the South China Sea is attributed to the midlatitude-tropic interactions through the East Asian cold surge flows. In midlatitudes, the occurrence of the East Asian cold surge flow is juxtaposed between the surface high and low of a dipole in northeastern Asia. The tropical trade easterlies are intensified by the cold air outbreak in the open ocean linked to the formation of the explosive cyclone. In the tropics, the formation of $\operatorname{CSV}\left(\mathrm{HRF}_{m}^{n}\right)$, the intensification of $\operatorname{CSV}\left(\mathrm{HRF}_{m}^{3}\right)$ to reach its second peak intensity, and the formation of $\mathrm{HRF}^{3}$ events are achieved through the multi-interactions of the parent CSV(HRF) with the East Asian cold surge flows. The difficulty to forecast the occurrence of $\mathrm{HRF}_{m}^{3}$ events is attributed to the accuracy of coherent predictions for the related synoptic activities in both midlatitudes and the tropics.

Acknowledgments. The Cheney Research Fund and NSF Grant ATM-0836220 sponsored this study. Jun Matsumoto's contribution to this study is supported by the Grant-in-Aid for Scientific Research (26220202) from the Japan Society for the Promotion of Science. Comments and suggestions offered by two anonymous reviewers are very helpful in improving the presentation of this study.

\section{REFERENCES}

Cheang, B. K., 1977: Synoptic feature and structure of some equatorial vortices over the South China Sea in the Malaysian region during the winter monsoon of December 1973. Pure Appl. Geophys., 115, 1303-1333, doi:10.1007/BF00874411.

Chen, T.-C., 1985: Global water vapor flux and maintenance during FGGE. Mon. Wea. Rev., 113, 1801-1819, doi:10.1175/ 1520-0493(1985)113<1801:GWVFAM>2.0.CO;2.

_ , and M.-C. Yen, 1991a: Intraseasonal variations of the tropical easterly jet during 1979 northern summer. Tellus, 43A, 213225, doi:10.1034/j.1600-0870.1991.t01-2-00004.x.

— with the Madden-Julian oscillation. J. Geophys. Res., 96 (D7), 13 163-13 177, doi:10.1029/91JD01356.

_, W.-R. Huang, and J.-H. Yoon, 2004: Interannual variation of the East Asian cold surge activity. J. Climate, 17, 401-413, doi:10.1175/1520-0442(2004)017<0401:IVOTEA > 2.0.CO;2.

— Forecast advisory for the late fall heavy rainfall/flood event in central Vietnam developed from diagnostic analysis. Wea. Forecasting, 27, 1155-1177, doi:10.1175/WAF-D-11-00104.1.

,,,--- N. T. T. Thanh, and J. Alpert, 2012b: Synoptic development of the Hanoi heavy rainfall event of 30-31 October 2008: Multiple-scale processes. Mon. Wea. Rev., 140, 1219-1240, doi:10.1175/MWR-D-11-00111.1.

_ J.-D. Tsay, M.-C. Yen, and J. Matsumoto, 2013a: The winter rainfall of Malaysia. J. Climate, 26, 936-958, doi:10.1175/ JCLI-D-12-00174.1.

,,--- , and,$- 2013 \mathrm{~b}$ : Interannual variation of the winter rainfall in Malaysia. J. Climate, 26, 4630-4648, doi:10.1175/JCLI-D-12-00367.1.

,,-- J. Matsumoto, and J. Alpert, 2015: Development and formation mechanism of the Southeast Asian winter heavy rainfall events around the South China Sea: Part I: Formation and propagation of cold surge vortex. J. Climate, 28, 14171443, doi:10.1175/JCLI-D-14-00170.1.

DFO, 2013: Global active archive of large flood events. Dartmouth Flood Observatory. [Available online at http:// floodobservatory.colorado.edu/.]

Greenfield, R. S., and T. N. Krishnamurti, 1979: The winter monsoon experiment-Report of December 1978 field phase. Bull. Amer. Meteor. Soc., 54, 439-444.

Johnson, R. H., 2005: Mesoscale processes. The Asian Monsoon, B. Wang, Ed., Springer, 331-356.

— Asian monsoon. Monsoon Meteorology, C.-P. Chang and T.N. Krishnamurti, Eds., Oxford University Press, 298-353.

Sanders, F., and J. R. Gyakum, 1980: Synoptic-dynamic climatology of the "bomb". Mon. Wea. Rev., 108, 1589-1606, doi:10.1175/ 1520-0493(1980)108<1589:SDCOT>2.0.CO;2.

von Storch, H., and F. W. Zwiers, 2002: Statistical Analysis in Climate Research. Cambridge University Press, 484 pp.

Yanai, M., S. Esbensen, and J.-H. Chu, 1973: Determination of bulk properties of tropical cloud clusters from large-scale heat and moisture budgets. J. Atmos. Sci., 30, 611-627, doi:10.1175/ 1520-0469(1973)030<0611:DOBPOT >2.0.CO;2.

Yokoi, S., and J. Matsumoto, 2008: Collaborative effects of cold surge and tropical depression-type disturbance on heavy rainfall in central Vietnam. Mon. Wea. Rev., 136, 3275-3287, doi:10.1175/2008MWR2456.1. 